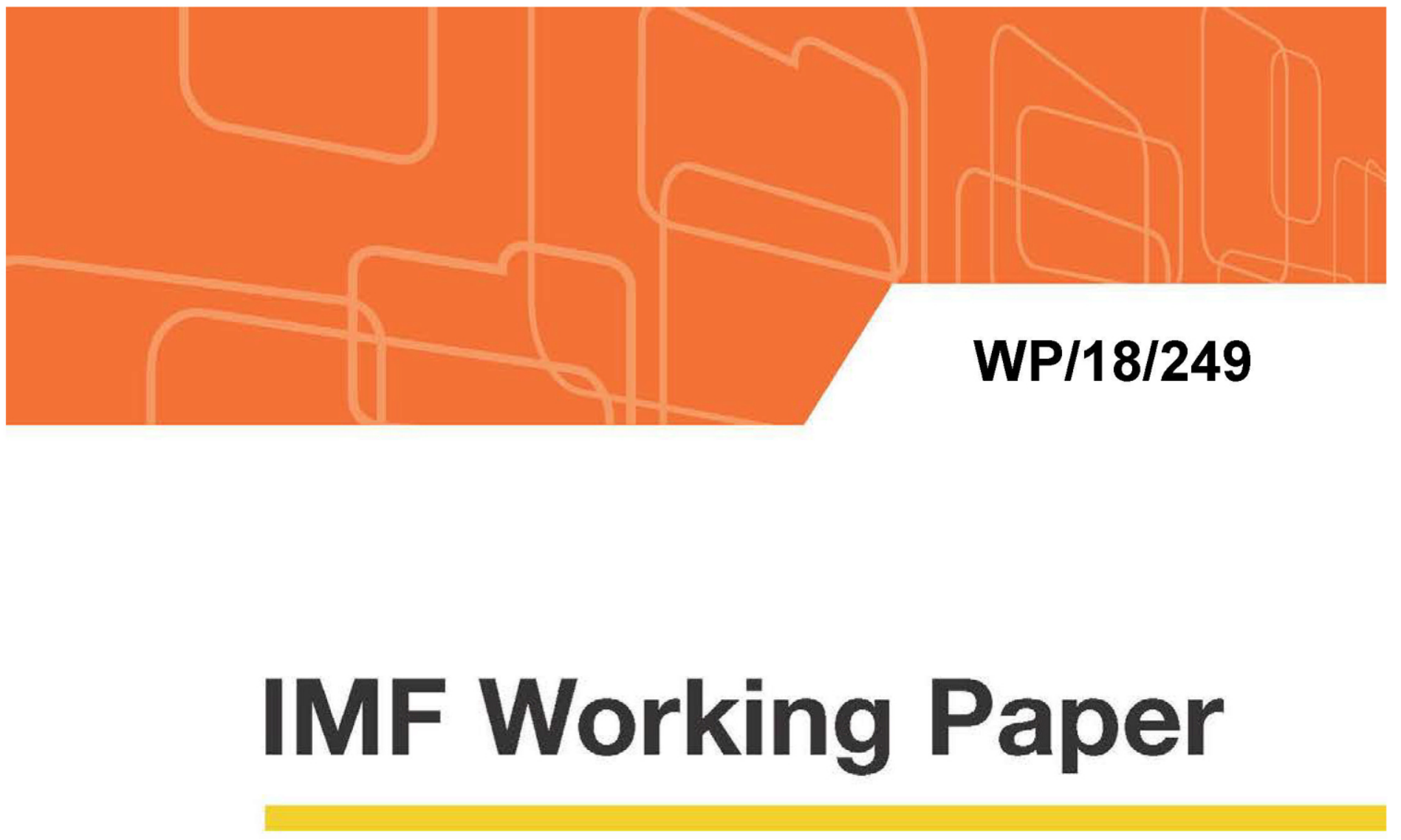

\title{
On Financing Retirement, Health, and Long-term Care in Japan
}

by Ellen R. McGrattan, Kazuaki Miyachi, and Adrian Peralta-Alva

IMF Working Papers describe research in progress by the author(s) and are published to elicit comments and to encourage debate. The views expressed in IMF Working Papers are those of the author(s) and do not necessarily represent the views of the IMF, its Executive Board, or IMF management. 


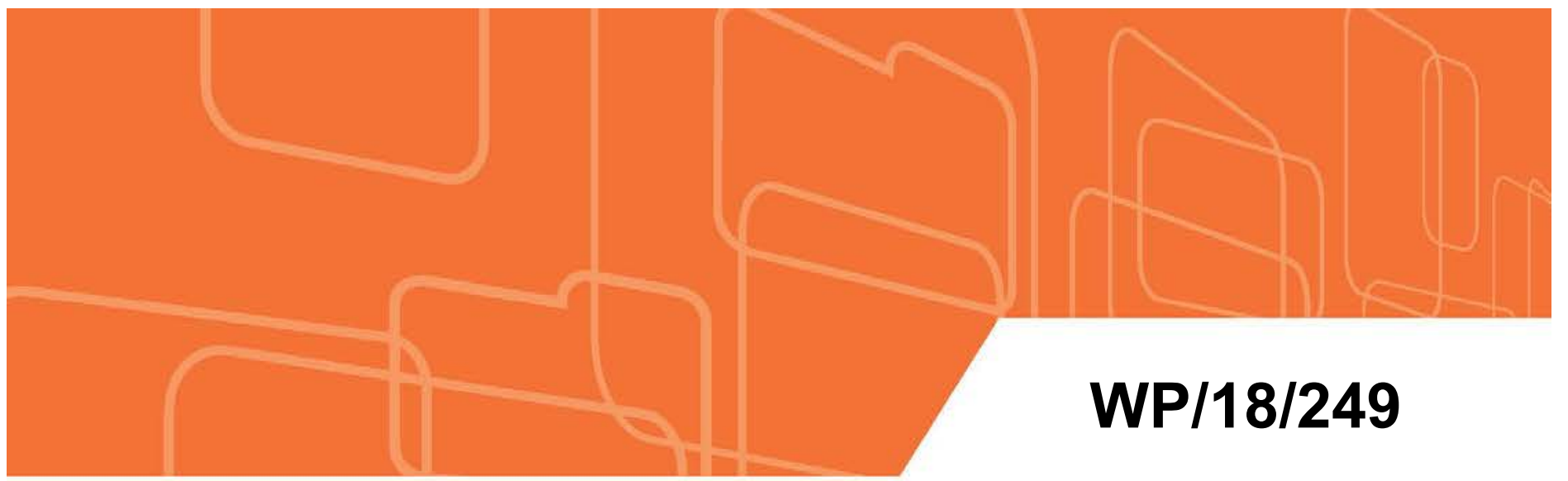

\section{IMF Working Paper}

\section{On Financing Retirement, Health, and Long-term Care in Japan}

by Ellen R. McGrattan, Kazuaki Miyachi, and Adrian Peralta-Alva

IMF Working Papers describe research in progress by the author(s) and are published to elicit comments and to encourage debate. The views expressed in IMF Working Papers are those of the author(s) and do not necessarily represent the views of the IMF, its Executive Board, or IMF management.

$$
\text { I N T E R N A T I O N A L M O N E T A R Y F U N D }
$$




\title{
IMF Working Paper
}

Asia and Pacific Department and Fiscal Affairs Department

\author{
On Financing Retirement, Health, and Long-term Care in Japan * \\ Prepared by Ellen R. McGrattan, Kazuaki Miyachi, and Adrian Peralta-Alva \\ Authorized for distribution by Paul Cashin and Catherine Pattillo
}

November 2018

\begin{abstract}
IMF Working Papers describe research in progress by the author(s) and are published to elicit comments and to encourage debate. The views expressed in IMF Working Papers are those of the author(s) and do not necessarily represent the views of the IMF, its Executive Board, or IMF management.
\end{abstract}

\begin{abstract}
Japan faces the problem of how to finance retirement, health, and long-term care expenditures as the population ages. This paper analyzes the impact of policy options intended to address this problem by employing a dynamic general equilibrium overlapping generations model, specifically parameterized to match both the macroeconomic and microeconomic level data of Japan. We find that financing the costs of aging through gradual increases in the consumption tax rate delivers a better macroeconomic performance and higher welfare for most individuals than other financing options, including those of raising social security contributions, debt financing, and a uniform increase in health and long-term care copayments.

JEL Classification Numbers: H51,H55, I13, E62

Keywords: retirement, health care, taxation, aging, Japan

Authors’ E-Mail Addresses: erm@umn.edu; KMiyachi@imf.org; APeralta-Alva@,imf.org

"We thank Paul Cashin, David Coady, Vitor Gaspar, Callum Jones, Sagiri Kitao, Weicheng Lian, Maria Luz MorenoBadia, Catherine Pattillo, Roberto Piazza, Pau Rabanal, Todd Schneider, Baoping Shang, Junji Ueda and participants in meetings and seminars at Japan Ministry of Finance and the IMF. McGrattan is a professor of economics at the University of Minnesota and a consultant at the Federal Reserve Bank of Minnesota; Miyachi and Peralta-Alva are economists in the IMF's Asia and Pacific Department and Fiscal Affairs Department, respectively. The views expressed herein are those of the authors and not necessarily those of the Federal Reserve Bank of Minneapolis or the Federal Reserve System, the IMF, its Executive Board, or IMF management.
\end{abstract}




\section{Content}

Abstract

1. Introduction

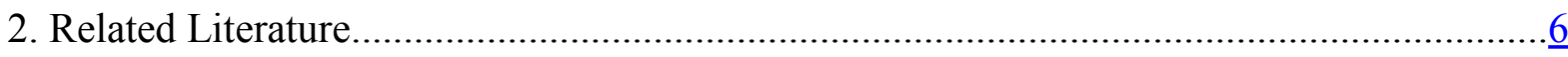

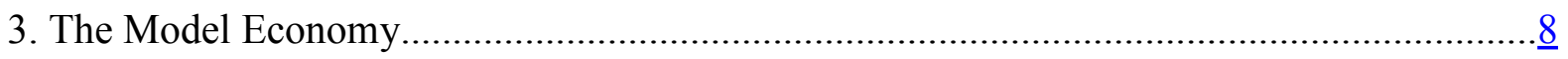

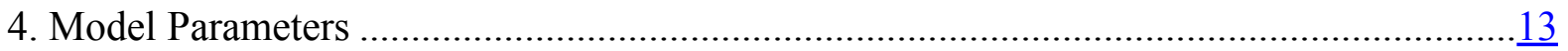

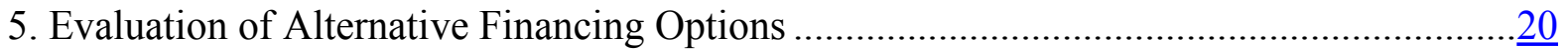

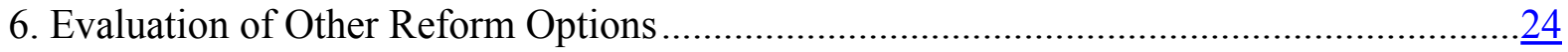

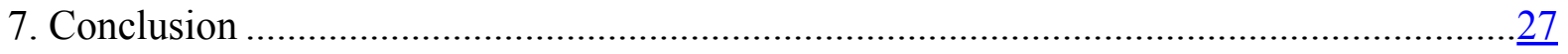

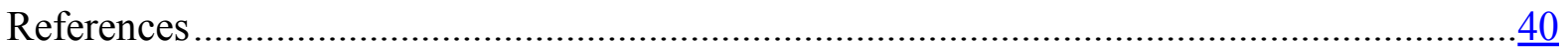

\section{Tables}

1. Adjusted National Income and Product Accounts for 2015 ................................................29

2. Adjusted Fixed Asset Tables with Stocks End of Period for 2015 .....................................

3. Parameters of the Model Economy Calibrated to Japan's Data .........................................

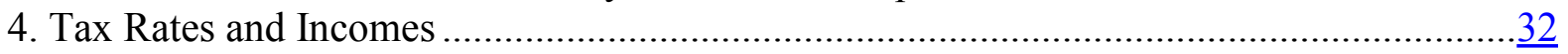

Figures

1. Old-age Dependency Ratios, Japan and the Next 10 Highest OECD Countries ................... $\frac{33}{33}$

2. Old-age Related Spending, Japan and OECD Countries ................................................

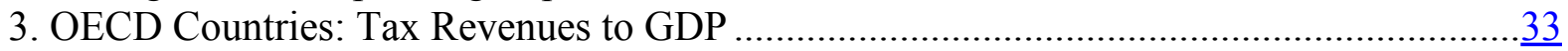

4. Japan: Health Transfers and Copayments by Age …………………………….................

5. Earning Patterns by Productivity Type and Age .............................................................

6. Aging Costs: Total and Health plus Long-term Care ……..............................................

7. Consumption Taxes Under Different Scenarios .............................................................

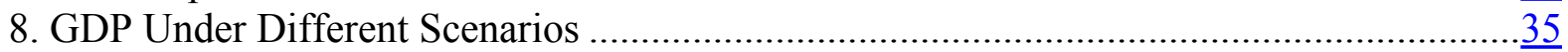

9. Sources of Government Revenue Under the Preferred Policy Scenario................................

10. Financing Aging Costs Through Increases in Contributions............................................

11. Welfare Effects of Financing Aging Costs Through Increases in Contributions ................

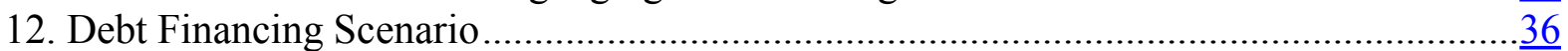

13. Changes in Interest Rates Under the Baseline and in Debt Financing Scenario .................

14. Crowding out of Private Sector Investment in Debt Financing Scenario ...........................

15. Welfare Effects of Debt Financing Scenario ………………………..........................

16. Welfare Effects of Increasing Copayment Rates ...........................................................

17. VAT Adjustment Under Favorable Demographics, or Improved Efficiency in Health

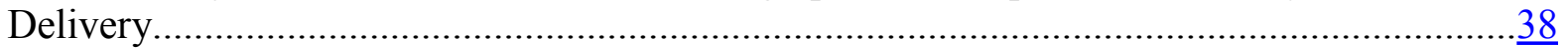

18. GDP Under Favorable Demographics, or Improved Efficiency in Health Delivery ........... $\frac{38}{39}$

19. GDP when TFP Growth Accelerates ………….........................................................

20. Consumption Taxes when TFP Growth Accelerates .....................................................

\section{Appendix}

1. Assumptions on Pension Transfers 


\section{Introduction}

Many countries are facing the challenging policy issue of how to finance retirement, health, and long-term care expenditures as the number of workers per retiree falls. In this context, Japan is the OECD frontrunner: Japan's population started declining around 2009, and is expected to fall by more than 25 percent, from 126 to 94 million, between 2017 and 2060; the old age dependency ratio - the ratio of individuals aged 65 and over to individuals 15 to 64-was 44 percent in 2016, more than 10 percentage points higher than the average of the next 10 highest OECD countries (see Figure 1). Population projections suggest that Japan will remain the country with the highest old age dependency ratio, surpassing 70 percent by 2060, while the average for the next ten highest OECD countries is forecasted to be 54 percent.

These demographic trends, combined with the fact that Japan's age-related government outlays (shown in Figure 2) are among the highest in the OECD, will further increase age-related costs, while putting downward pressure on both aggregate and per capita GDP. The fact that the government debt-to-GDP ratio is the highest among OECD countries (at 2.4 times GDP), while tax revenues are well-below the OECD average (shown in Figure 3), only exacerbates these challenges. Thus, when financing retirement, health, and long-term care of its elderly, Japan needs to strike a delicate balance between the objectives of protecting growth and welfare, and putting debt on a stable path.

The Japanese government has already implemented some important reforms - most notably a macro-indexing mechanism in the pension system with the aim of controlling the aggregate pension spending as a percent of GDP. However, more needs to be done. Of particular concern is the additional funding needed for the universal health and long-term care systems, which are part of the Japanese social security system. Per adult spending on health and long-term care (shown in Figure 4) rises exponentially with age, making this portion of aging costs particularly expensive in light of Japan's worsening demographic trends. Indeed, given rapid increases in health and longterm care costs during the past decade, recent work has focused more attention on these components of aging costs. Nozaki and others (2017), for instance, estimate that health and long-term care costs could increase from roughly 9.5 percent of GDP in 2010 to a level in the range of 13 to 15.5 percent by 2030 .

Japanese policymakers and other institutions such as the IMF are discussing a number of 
options to address these problems (see IMF 2016, 2017). On the financing side, the options include increasing consumption taxes, increasing social security contributions to finance health care costs, and increasing copayment rates for health and long term care. ${ }^{1}$ In this paper, we analyze the impact of these policy options by employing a dynamic general equilibrium overlapping generations model, specifically parameterized to match both the macro and micro level data of Japan.

Our preferred financing option, which allows for debt to be stabilized, requires continued but very gradual increases in the consumption tax rate and has relatively benign effects on macroeconomic activity and welfare. This financing option results in substantial long run gains relative to alternative financing options in terms of GDP, private investment to GDP, and welfare. To arrive at this conclusion, we compute equilibrium transition paths, with the initial state calibrated to Japan in 2015, referred to later as the "current Japanese economy." We allow for within-cohort heterogeneity, with differences arising from differences in productivity. This allows us to explore the impacts of alternative policies on different birth cohorts and income groups. The simulated data from the model we use is consistent with both Japanese national income and product accounts and the income distribution.

The transitions involve both changes in demographics and changes in taxes and government transfers. We model the current Japanese economy departing from the current composition of the population, and use demographic forecasts from the National Institute of Population and Social Security Research (IPSS) so that the old age dependency ratio reaches around 75 percent by 2060. In addition to Japan's demographic transition we introduce the different policies being proposed. We first consider a tax-transfer system, with consumption tax rates as the only variable that adjusts over time in order to keep government debt stable at about 200 percent of GDP (the current value of gross debt minus pension fund financial assets). As the population ages, consumption taxes rise to finance the additional old-age transfers, as required by the government budget constraint to keep the debt-to-GDP ratio unchanged. This will turn out to be the preferred policy scenario (and will serve as our baseline). The consumption tax rate in this scenario peaks at about 20 percent.

We then compare the results of the baseline scenario with other scenarios defined by the use of other policy variables that may contribute to financing the costs of retirement, health, and

\footnotetext{
${ }^{1}$ Other policies are aimed at increasing fertility rates, improving the efficiency of health services, and raising economy wide productivity.
} 
long-term care. In all scenarios, consumption taxes are adjusted period by period to satisfy the government's budget constraint.

The first alternative scenario considers increases in social security contributions to finance increasing health and long term care costs. This policy is implemented through gradual (and even across income brackets) increases in effective tax rates on labor income over 20 years, peaking at an 8 percentage points increase and remaining indefinitely at that new higher rate. Under this scenario consumption tax rates would still need to increase significantly, by roughly 8 percentage points, to keep the debt-to-GDP ratio stable. Labor income taxes are more distortive than consumption taxes and, therefore, GDP falls significantly. This would be particularly relevant for future generations, who would experience long-run GDP losses on the order of 7 percent relative to the preferred policy. Average welfare is also 5 percent lower for future generations than under the preferred policy scenario.

An alternative scenario we study is the case of further inaction. This means debt accumulates at a pace such that consumption tax rates remain unchanged for about 15 years; from then on we assume debt grows at a constant pace until 2040. Consumption taxes adjust along the way to satisfy the government budget constraint and assumed government debt path. Under this scenario, debt reaches 300 percent of GDP, causing a substantial crowding out of private investment. Government debt is held domestically and it is assumed to have an unchanged rate of interest, which is lower than the rate of return of private capital. Hence, higher government debt reduces the return of the portfolio of households. The private sector must pay a higher rate of interest to motivate households to save and channel resources into the financial system. According to the model predictions, the ratio of private investment to GDP declines by up to 8 percent relative to the preferred policy scenario. Because the long run level of debt is higher, consumption tax rates must increase to roughly 30 percent in order to stabilize the debt-to-GDP ratio. The overall effect of these changes is a long-run GDP level that is 20 percent lower than under the preferred policy.

Debt or higher income taxation scenarios benefit retirees and older workers as they care mostly about current consumption, and both policies either delay the increase in the consumption tax rate or require a lower level for the rate. Their relatively small gains come at the expense of current workers and all future generations across the income spectrum.

The next scenario we consider explores the effects of increasing the health and long-term care

CInternational Monetary Fund. Not for Redistribution 
copayment rates for the elderly. In particular, we allow the health copayment rate paid by people over 65 to rise gradually over a 20-year period to the same level as that of the working age population. We find this policy results in relatively small gains and the required adjustment in consumption taxes is only reduced by more than 2 percentage points. Data show health spending per adult is very similar across the income spectrum. Hence, increasing health copayment rates is regressive, affecting poor and middle class workers disproportionately. Welfare losses for the latter groups can reach 6 percent of lifetime welfare under this policy.

The last set of experiments considers the sensitivity of the model, and our estimates of government financing needs, to more favorable assumptions on demographic trends, efficiency of the health sector, and improvements in economy wide productivity. In the case of demographic trends, we use more favorable fertility predictions from the IPSS. In the case of efficiency improvements, we assume less spending is required for the same level of health services. In both cases, we require a smaller increase in consumption tax rates, by roughly 3 percentage points, when compared with our preferred policy scenario. Higher productivity does not necessarily reduce the fiscal burden of aging costs substantially, given that the pension transfers are linked with real wage developments and health transfers have grown faster than per capita GDP.

In Section 2, we discuss the related literature. Section 3 presents the model used to evaluate the alternative retirement financing systems. Section 4 discusses the model parameters that are chosen to be consistent with macro and micro data from Japan. Results of our policy experiments are reported in Sections 5 and 6. In Section 7, we conclude.

\section{Related Literature}

The literature concerned with financing aging costs is large and growing. The Feldstein (1998) volume is a useful collection of papers that consider saving-for-retirement systems in the United States, Chile, Australia, the United Kingdom, Mexico, and Argentina. Conesa and Garriga (2008) consider a set of social welfare functions and derive optimal policies. They are interested in designing plans that are welfare improving for transitional generations. They show that such a plan is possible but find paths for tax rates, especially tax rates on capital income, that "call into question its relevance" as an actual policy option (p. 294). For example, in their baseline economy in which the 
government chooses both labor and capital income tax rates, the optimal capital income tax rate oscillates between 60 percent and -60 percent. In the case of Japan, an imminent issue is how to address aging costs under its generous and well-established social security system. Therefore, we focus attention on policies that are currently being discussed by Japanese policymakers and IMF. ${ }^{2}$

Based on historical data, the IMF (2010) performs a partial equilibrium accounting analysis and finds that gradual increases in the consumption tax rate - rising to a 15 percent rate in the long run-paired with some expenditure reforms would suffice to guarantee the sustainability of public finances. Recent quantitative general equilibrium analyses suggest much larger adjustments are required. Kitao (2015) employs an overlapping generations model calibrated to Japan. In her baseline experiment, for debt to remain stable, the consumption tax rate must rise to 19.3 percent in the long run, with larger adjustments needed during the transition. Similar results and large fiscal adjustment needs are also reported in general equilibrium settings considered by Braun and Joines (2015) and Imrohoroglu and Sudo (2011). These general equilibrium analyses, however, do not consider the welfare implications of reforms of the health system, do not model within cohort heterogeneity, and do not assume progressive income taxes. We find that all of these features are necessary to analyze potential reform options in Japan, as different types of workers are subject to different benefits and tax rates in the current system, and government authorities are interested in the distributional impact of policy changes on welfare.

Imrohoroglu, Kitao and Yamada (2016) perform a very rich partial equilibrium analysis of pensions and pension reform. Their analysis includes key features of the pension system, heterogeneous types of workers, and a detailed matching of life cycle consumption, work and savings patterns. These authors find that, under unchanged policies, pension and non-pension spending, which includes health and long term care expenditures plus other forms of government spending, would contribute more or less equally to the fiscal deficit and that debt is on an unsustainable path. They conclude that debt sustainability can be ensured by increasing consumption tax rates to about 20 percent, increasing the retirement age to 70, and cutting pension benefits by 10 percent. They do not consider the welfare impact of alternative policy options. Our analysis also includes workertype heterogeneity, is consistent with life cycle micro data, and includes pension spending paths

\footnotetext{
${ }^{2}$ For the authorities' policy discussions, see the "Basic Policy on Economic and Fiscal Management and Reform 2018."
} 
consistent with the data and pension system of Japan. However, we do so in a general equilibrium framework, which is necessary for estimating the joint macroeconomic and welfare implications of alternative policy scenarios under consideration. For example, the large crowding out effects associated to the scenario of further inaction would be difficult to sort out in a partial equilibrium setting where prices and behaviours do not respond to the policy environment.

To summarize, the main contribution of this paper to the literature is performing a general equilibrium analysis of reforms being discussed by Japanese policymakers and the IMF to deal with the costs of aging. We also take into account key sources of heterogeneity of the labor force, matching life time work and saving patterns, and allow for health, long term care, and pension paths that are consistent with the Japanese data and policy framework.

\section{The Model Economy}

In what follows, we adopt the modeling approach of McGrattan and Prescott (2017), with Japanspecific refinements. The model economy has an OLG structure with measure $n_{t}^{1, k}$ arriving as working-age households with productivity level $k \in\{1,2, \ldots, K\}$ at the beginning of date $t$. The year since entry into the workforce is called age and is denoted by $j$. The measure of age $j$ households with productivity level $k$ at date $t$ is $n_{t}^{j, k}$. The maximum possible age is $J$. The probability of an age $j<J$ household of any type at date $t$ surviving to age $j+1$ is $\sigma_{t}^{j}>0$. The $n_{t}^{1, k}$ are parameters that define the population dynamics. We restrict attention to

$$
n_{t+1}^{1, k}=\left(1+\eta_{t}\right) n_{t}^{1, k}
$$

with $\sum_{k} n_{0}^{1, k}=1$, where $\eta_{t}$ is the growth rate of households entering the workforce.

\subsection{State Vector}

To simplify notation, we use recursive competitive equilibrium language. Given that the economy is non-stationary, $t$ is included as an element of the aggregate state vector. All stocks are beginning of period stocks. The variables that define the aggregate state vector $s$ are as follows:

(i) $t=0,1,2, \ldots$, is the time period. 
(ii) $\left\{a^{j, k}, n^{j, k}\right\}$ are the assets $a^{j, k}$ (net worth) of an age $j$, type $k$ household, and $n^{j, k}$ is the measure of these households.

(iii) $B$ is government debt.

(iv) $K_{T 1}$ and $K_{T 2}$ are aggregate tangible capital stocks for two business sectors (described below).

(v) $K_{I 1}$ and $K_{I 2}$ are aggregate intangible capital stocks for two business sectors.

Two business sectors are needed because different legal categories of businesses are subject to very different tax systems and, as a consequence, the market values of their equity and debt relative to their capital stock are different. The empirical counterpart of sector 1 are businesses that are subject to the corporate income tax. Unincorporated household businesses are categorized in sector 2, which distribute all profits to owners.

\subsection{Portfolios and the return of assets}

To match the data of Japan it is important that the model can accommodate a large amount of debt held by the public, which pays a relatively low interest rate, and thus results in a relatively small burden on the government budget, as in the actual Japanese data. To achieve this, and the key modification of our model relative to that of McGrattan and Prescott (2017) we follow Braun and Joines (2015) and Kitao (2015), whereby individuals are assumed to save in shares of ownership of an asset constituted by a fraction $\phi_{t}$ of government debt, and a fraction $1-\phi_{t}$ of claims to the flows from private firms' capital. Hence, the rate of return of the only financial asset available is a weighted average of the returns of government debt and private capital. The interest

rate on government bonds is exogenously determined and given by sequence $\left\{i_{t}^{d}\right\}$. As the capital account is assumed to be closed, total asset holdings in this composite financial asset must equal government debt and the private sector for equilibrium in financial markets to hold. Hence, given the exogenous stock of government debt and its interest rate, fraction $\phi_{t}$ will be computed as part of equilibrium so as to guarantee the assumed fractions of assets in the portfolio.

\subsection{Prices and Policy}

The relevant equilibrium price sequences for the households are government debt and private capital interest rates $\left\{i_{t}^{d}, i_{t}^{k}\right\}$ and wage rates $\left\{w_{t}\right\}$. 
Policy specifies the following sequences:

(i) Tax rates $\tau=\left\{\tau_{t}^{c}, \tau_{1 t}^{d}, \tau_{2 t}^{d}, \tau_{1 t}^{\pi}\right\}$, where $c$ denotes consumption, $d$ distributions from businesses to their owners, and $\pi$ profits. Note that sector 2 businesses are not subject to the corporate profit tax and must distribute all their profits to their owners.

(ii) Effective tax schedules on labor income $\left\{T_{t}^{w}(\cdot)\right\}$

(ii) Exogenously given transfers (constituted by pension transfers; and also by health (plus long term) care transfers $\left.\left\{T_{t}^{j, k, p}, T_{t}^{j, k, h}\right\}\right)$ that are time, age, and productivity-type dependent).

(iv) Government debt $\left\{B_{t}\right\}$.

(v) Pure public good consumption $\left\{G_{t}\right\}$, defined as a fraction of GDP: $G_{t}=\phi_{G t} G D P_{t}$.

\subsection{The Households' Problem}

The value function of a household of age $j \in\{1,2, \ldots, J\}$ with productivity level $k \in\{1,2, \ldots, K\}$ satisfies

$$
v_{j}(a, s, k)=\max _{a^{\prime}, c, \ell \geq 0}\left\{u(c, \ell)+\beta \sigma_{t}^{j} v_{j+1}\left(a^{\prime}, s^{\prime}, k\right)\right\}
$$

subject to

$$
\begin{gathered}
c+\tau_{c_{t}}\left(c-T_{t}^{j, k, h}-\chi_{t}^{j, k, h}\right)+a^{\prime} \sigma_{t}^{j} \\
=\left\{\phi_{t}\left(1+i^{d}\right)+\left(1-\phi_{t}\right)\left(1+i^{k}\right)\right\} a+y_{t}-T_{t}^{w}\left(y_{t}\right)+T_{t}^{j, k, p}+T^{j, k, h} \\
y_{t}=w_{t} l \epsilon^{j, k} \\
c \geq T_{t}^{j, k, h}+\chi_{t}^{j, k, h} \\
s^{\prime}=F(s)
\end{gathered}
$$

Symbol $\ell$ denotes the labor services of a household. Productivity $k$ household knows with certainty its type and age dependent productivity profile $\epsilon^{j, k}$. The prime denotes the next period value of a variable and $v_{J+1}=0$. As discussed earlier, savings are in shares of ownership of an asset that makes payments to members of a cohort in their retirement years conditional on them being alive. Effectively, the return on savings depends on the return of the asset, but also on the survival 
probability. As described in the right hand side of the household's budget constraint, each household is subject to labor income tax $T_{t}^{w}(\cdot)$, while receiving pension and health transfers $\left(T_{t}^{j, k, p}, T_{t}^{j, k, h}\right)$. We count corresponding health spending as part of consumption, $c$, for welfare calculations. But in Japan, health expenditures are not subject to consumption taxes, which is described as $\tau_{c t}(c-$ $\left.T_{t}^{j, k, h}-\chi_{t}^{j, k, h}\right)$ on the left hand side of the household's budget constraint. We impose the condition that consumption must be at least equal to health and long term care transfers, including individual health copayments $\chi_{t}^{j, k, h}$.

We make the simplifying assumption that pension and health and long term care are lump sum transfers (depending only on time, household type, and age) from the government. As we document later on, this is roughly consistent with the data.

Aggregate labor supply $L$ is

$$
L=\sum_{j, k} n^{j, k} \ell^{j, k} \epsilon^{j, k}
$$

The equilibrium law of motion of the aggregate state variable, $F$, is taken as given by the private agents.

\subsection{Technology}

One sector is subject to the corporate income tax and produces intermediate good $Y_{1 t}$, and one sector produces intermediate good $Y_{2 t}$. The aggregate production function of the composite final good is

$$
Y_{t}=Y_{1 t}^{\theta_{1}} Y_{2 t}^{\theta_{2}}
$$

where the exponents are positive and sum to 1.

The aggregate sectoral production function is Cobb-Douglas with inputs of tangible capital $K_{i T t}$, intangible capital $K_{i I t}$, and labor $L_{i t}$ :

$$
Y_{i t}=K_{i T t}^{\theta_{i T}} K_{i I t}^{\theta_{i I}}\left(\Omega_{t} L_{i t}\right)^{1-\theta_{i T}-\theta_{i I}}
$$

for $i=1,2$. The labor-augmenting technical level at date $t$ in both sectors is $\Omega_{t}$, which grows at rate $\gamma$, so

$$
\Omega_{t+1}=(1+\gamma) \Omega_{t} .
$$


Capital stocks depreciate at a constant rate, so

$$
\begin{aligned}
K_{i T, t+1} & =\left(1-\delta_{i T}\right) K_{i T, t}+X_{i T t} \\
K_{i I, t+1} & =\left(1-\delta_{i I}\right) K_{i I t}+X i I t
\end{aligned}
$$

for $i=1,2$, where $T$ and $I$ denote tangible and intangible, respectively, and $X$ is investment. Depreciation rates are denoted as $\delta$ and are indexed by sector and capital type. The resource balance constraint is

$$
Y_{t}=C_{t}+X_{T t}+X_{I t}+G_{t}
$$

where $X_{T t}=\sum_{i} X_{i T t}$ and $X_{I t}=\sum_{i} X_{i I t}$.

\subsection{Government Budget Constraints}

Some notation must be set up before the law of motion for government debt can be specified. The prices of the intermediate good relative to the final good are $p_{1 t}$ and $p_{2 t}$. The accounting profits of corporations are given by

$$
\Pi_{1 t}=p_{1 t} Y_{1 t}-w_{t} L_{1 t}-X_{1 I t}-\delta_{1 T} K_{1 T t},
$$

and distributions to the corporations' owners are

$$
D_{1 t}=\left(1-\tau_{1 t}^{\pi}\right) \Pi_{1 t}-K_{1 T, t+1}+K_{1 T t} .
$$

Other business distributions to their owners are

$$
D_{2 t}=\Pi_{2 t}=p_{2 t} Y_{2 t}-w_{t} L_{2 t}-X_{2 I t}-\delta_{2 T} K_{2 T t} .
$$

We can now specify the law of motion of government debt:

$$
\begin{gathered}
B_{t+1}=B_{t}+i_{t} B_{t}+G_{t}-\sum_{j, k} n_{t}^{j, k}\left(T_{t}^{j}\left(w_{t} \ell_{t}^{j, k} \epsilon^{k}\right)-\left(T_{t}^{j, k, p}+T_{t}^{j, k, h}\right)\right) \\
-\tau_{t}^{c}\left(C_{t}-T_{t}^{h}-\chi_{t}^{h}\right)-\tau_{1 t}^{\pi} \Pi_{1 t}-\tau_{1 t}^{d} D_{1 t}-\tau_{2 t}^{d} D_{2 t} .
\end{gathered}
$$


Thus, next period's debt is this period's debt plus interest on this period's debt, plus public consumption, minus tax revenues (net of transfers). Taxes are levied on labor income and consumption (excluding health transfers and copayments), on profits of corporations, on corporate distributions to their owners, and on distributions of other business firms to their owners.

\subsection{Equilibrium Conditions}

The equilibrium conditions are as follows:

(i) Labor, capital, and goods markets clear at each point in time.

(ii) The household policy functions $\left\{a^{\prime}=f_{j}(s, k)\right\}_{j}$ imply the aggregate law of motion $s^{\prime}=F(s)$.

\section{Model Parameters}

We choose parameters of the model so that key features of equilibrium time series from our baseline model are consistent with the National Accounts of Japan (published by the Cabinet Office, henceforth referred to as the "JSNA") and with the distribution of individual incomes reported in the Statistical Survey of Actual Status for Salary in the Private Sector and the Sample Survey for Self-assessment Income Tax (both published by the National Tax Agency, henceforth referred to as the "Tax Surveys"). This is done in two steps. First, we set parameters governing demographics, household preferences, firm technologies, government spending and debt shares, and capital income tax rates so that the national accounts and fixed asset tables implied by the model are consistent with aggregate data. Second, we set population weights, productivity levels, transfers, and taxes on labor income to match micro data on population shares, labor income, transfer income, and tax rates.

\subsection{Macro Data}

We first describe the data for national income and product accounts, and fixed asset from the JSNA, as well as adjustments to make the accounts consistent with the model economy. Then, we discuss the parameters that are consistent with these data for 2015 . 


\subsubsection{National Account and Fixed Asset Tables}

Table 1 displays the Japanese national income and product accounts, after some of the standard adjustments that make model measurements and concepts consistent with the JSNA. Adjusted GDP is equal to JSNA GDP after subtracting consumption tax as it is assumed to be levied on private consumption.

We categorize income as "labor" or "capital." Labor income comprises 53 percent of total adjusted income, and mainly consists of compensation of employees. Seventy percent of households' mixed income (including private unincorporated enterprises) is also classified into labor income. Capital income includes all other categories of income, including the remaining 30 percent of households' mixed income as well as households' net operating surplus (imputed service of owner-occupied dwellings).

The product side is categorized into two categories: consumption and investment. Consumption comprises 75 percent of total adjusted product - private consumption of 63 percent and public consumption of 12 percent. Private consumption includes health and long-term care spending financed by the government, to be consistent with the model specification. This treatment enables us to compute households welfare in a comprehensive manner including health and long-term care. Health and long-term care spending are not subject to consumption taxes, and this is taken into account by our model specification detailed above. Investment includes gross private domestic investment, gross government investment, changes in inventories, and net exports, with an adjustment made for the consumption tax on gross capital formation. This category is 25 percent of adjusted total product.

Capital stocks are reported in Table 2. In line with the revision of JSNA in 2016 by adopting the 2008 SNA, fixed assets include both tangible and intangible assets. Private fixed assets amount to 229 percent of adjusted GDP, of which private corporates account for 68 percent and households account for the remaining 32 percent. Fixed assets owned by the government amount to 112 percent of adjusted GDP. Together, private and public fixed assets are equal to 340 percent of adjusted GDP. We also include land in the capital stock because it is in large part a produced asset associated with real estate development. With land included, the total capital stock is 566 percent of adjusted 
GDP. ${ }^{3}$

Table 3 reports the parameters used in the baseline economy - the economy with current Japanese demographics and policies. The first set of parameters governs demographics. For the baseline economy, we set the long term growth rate of the population equal to -1 percent and the survival probabilities to match the demographic transition with population projection for Japan under medium fertility rate (stable at around 1.4) and medium mortality rate assumption reported by the IPSS. Preference parameters are chosen so that the model's labor input and labor share are consistent with that of Japan. JSNA reported that average hours worked per employee are 1,751 hours per year in 2015. If discretionary time per week is 100 hours, then the fraction of time at work is 33.7 percent. Assuming logarithmic preferences, namely,

$$
u(c, \ell)=\log c+\alpha \log (1-\ell)
$$

we set $\alpha$ equal to 0.5 to get the same predicted hours of work for the model. In addition, we set $\beta=0.983$, so that the model's predicted division of income into labor and capital matches that of Japan shown in Table 1.

The technology parameters in Table 3 govern technological growth, investment rates, and capital income shares across business sectors. The long run growth rate of labor-augmenting technology is set equal to 1 percent. Together with the long term population growth rate of -1 percent-as implied by the demographic parameters described above - this results in a long run GDP growth rate of 0 percent. The share parameter in the aggregate production function $\theta_{1}$ - which determines the relative share of income to private corporations - is set equal to 64 percent. This parameter is based on the private corporates' proportion of operating surplus and mixed income.

As we noted earlier, we use data from JSNA to determine the relative quantities of investments and fixed assets for the model's two sectors. Accordingly, the choice of tangible capital shares $\left(\theta_{1 T}\right.$, $\left.\theta_{2 T}\right)$ and tangible depreciation rates $\left(\delta_{1 T}, \delta_{2 T}\right)$ ensures that the model's investments and fixed assets line up with tangible investments and stocks reported by JSNA. Doing so, we estimate tangible capital shares of $\theta_{1 T}=0.45$ and $\theta_{2 T}=0.15$ in the two sectors. The annual depreciation rates that

\footnotetext{
${ }^{3}$ Following McGrattan and Prescott (2017), we do not include human capital owned by individuals in our measure of the capital stock because retired people do not rent their human capital to the business sector and cannot sell it in order to finance retirement consumption.
} 
generate investment rates consistent with Japan's data are $\delta_{1 T}=0.06$ and $\delta_{2 T}=0.05$. The high capital share and low depreciation in sector 2 follow from the fact that we have included housing and land.

The intangible capital shares and depreciation rates, $\theta_{1 I}, \theta_{2 I}, \delta_{1 I}, \delta_{2 I}$, are not uniquely identifiable with the data we have. For the baseline model, we calibrate these parameters following Arato and Yamada (2012), who derive estimates of tangible and intangible assets for the corporate sector. We assume the same ratio for the intangibles to non-land fixed assets of the non-corporate sector to obtain an intangible assets estimate for this sector.

The last set of parameters in Table 3 includes fiscal policy parameters. $\phi_{B}$ is defined as gross general government debt subtracting financial assets held by public pension funds. Financial assets held by public pension funds are accumulated for future pension liabilities. However, in this model, future pension liabilities are also incorporated. We set the level of government consumption $\phi_{G}$ constant in percent of adjusted GDP for all periods. ${ }^{4}$

Capital tax rates are listed next in Table 3. The effective corporate income tax rate $\tau_{1}^{\pi}$ is set as 25 percent to match the model-implied corporate income tax with taxes on corporates' income and other current taxes paid by corporates in JSNA . An additional tax on distributions $\tau_{1}^{d}$ is paid by investors in these corporations, where distributions are in the form of dividends and share buybacks. This is set as 25 percent to adequately match capital income and the size of the corporate sector. Household business, our second category of businesses, is assumed to distribute their accounting earnings to their owners and whose earnings are treated as ordinary labor income tax. For the tax rates on this household business distributions $\left(\tau_{2}^{d}\right)$, we use an estimate of average tax rate on labor income of 29 percent (see below for details on labor income tax).

When we simulate the model using the parameters in Table 3, the model's national account and fixed asset statistics in 2015 are very close to those shown in Tables 1 and 2 for Japan.

\subsection{Micro Data}

In this section, we disaggregate labor income (captured as compensation of employees in JSNA), and estimate effective tax rates on labor income across income cohorts, using the Tax Surveys

\footnotetext{
${ }^{4}$ In order to focus on Japan's aging costs, $\phi_{G}$ is set to stabilize debt-to-GDP ratio at initial period based on other parameters, rather than using the actual data. This implies that initial primary deficit has not been incorporated in the calibration. Fiscal adjustment needs would be even larger if the initial imbalance were included.
} 
published by NTA. In addition, per capita pension and health care transfers are calibrated to match the aggregate fiscal data.

Individuals are assigned to different income brackets and, for each bracket, we construct population shares, income shares, and marginal and average tax rates. We then use estimates for these variables to set population weights, productivity levels, and the net tax schedules for workers and retirees.

\subsubsection{Income Distribution and Tax Rates}

In constructing the distribution of labor incomes and labor income tax rates, we use the Tax Surveys published by NTA. There are some data sources for income distributions, such as the National Survey of Family Income and Expenditure (hereinafter referred to as the "NSFIE"). However, the Tax Surveys have several important advantages for calibrating the model economy. Firstly, the aggregate labor income is very close to JSNA due to the wide coverage of Tax Surveys. ${ }^{5}$ Secondly, it is relatively straightforward to estimate labor income tax rates corresponding to income cohorts. Although the NSFIE has merits in capturing household based income, taxes and government transfers all together, it only captures monthly revenue and expenditure, making it difficult to match with aggregate annual data. In particular, given the monthly data do not capture bonuses, which are important factor especially in the context of Japan, income distribution and corresponding tax rates estimated using this data would require substantial adjustments. Instead, we rely on the Tax Surveys for income distributions and tax rates, while using micro data for pension and health care transfers across ages.

In Table 4, we report the distribution of labor income grouped in 14 income brackets. Labor income taxes (including social security contributions) in each bracket are estimated by following steps:

(i) National personal income tax can be directly obtained by the Tax Surveys.

(ii) Data on local income taxes are not directly available from the Tax Surveys. Instead, taxable income is estimated from aggregate income in each income cohort, the number of workers who benefit from various income deductions (proxy of which can be obtained from national tax data),

\footnotetext{
${ }^{5}$ There are some differences in coverage. For example, Tax Surveys do not cover compensation of employees for public officials.
} 
and the maximum amount of income deduction for local taxes. Then, local income taxes are estimated by multiplying the taxable income for each income by the statutory tax rate.

(iii) Social security contributions are also estimated from the Tax Surveys since it records the amount of social security contributions in each income bracket for calculating income deductions. ${ }^{6}$

The last column of Table 4 provides the estimates of effective income tax rates across income brackets. In spite of the progressivity of the tax structure, social security contributions are regressive, with flat rates for middle incomes. The latter highlights the importance of capturing social security contributions in addition to national and local income taxes.

\subsubsection{Parameters Based on Income Distribution and Tax Data}

The next step is to set the parameters relevant for the model's predicted distributions of income and taxes. Specifically, we show how we use the data from Table 4 to estimate the productivity levels, $\epsilon^{k}$, and the initial tax schedules $T_{0}^{j}(\cdot)$.

For our baseline parameterization, we assume that there are four types of labor that differ in terms of their levels of productivity; we refer to the types as low, medium, high, and top 1 percent. The value of $\epsilon^{k}$ for the low types is chosen so that the share of their lifetime labor income (average over aged 18 to 65 ) in the model matches the share of labor income in brackets covering under $¥ 2$ million. This type comprise 32 percent of the population over 18 years old. Similarly, the values of $\epsilon^{k}$ for the medium, high, and top 1 percent types are chosen so there is a match between the group's lifetime labor income share in the model and that of $¥ 2$ million to $¥ 4$ million, $¥ 4$ million to $¥ 15$ million, and over $¥ 15$ million, respectively. The population shares for the medium and high are 31 and 36 percent, respectively. Per capita earnings in each productivity type is normalized relative to the average earnings. This gives us shares in total labor income from the lowest to highest types equal to $8,25,61,6$ percent, respectively.

It is also important to note that labor income typically increases up to 50 years old then decreases until retirement as illustrated in the Basic Survey on Wage Structure published by Ministry of Health, Labor, and Welfare (MHLW). In the data, non regular workers earnings paths do not grow much with age (which some attribute to the lack of incentives for firms to provide training to

\footnotetext{
${ }^{6}$ Our estimates of adjusted earnings and social security contributions include corporates' contributions in line with the definition of compensation of employees in JSNA.
} 
workers), and we assume flat profiles. For regular workers productivity paths fed into the model correspond to quadratic interpolations of the data from the Basic Survey on Wage Structure (see Figure 5).

To parameterize the initial tax schedule, $T_{0}^{j}(\cdot)$, we use data shown in the last column of Table 4. We assume that the tax schedule only depends on labor income, $T_{0}^{j}(y)=T^{w}(y)$, where $T^{w}(y)=\beta_{i} y$ on each income intervals $\left[\underline{y}_{i}, \bar{y}_{i}\right], i=1, \ldots, 14$. As noted earlier, we assume uniform tax rates on distributions from corporations and household business.

\subsubsection{Pension Benefits, and Health and Long-term Care}

The final step is the estimation of pension and health transfers, $T^{p}$ and $T^{h}$. In the transition period of 30 years up to 2048, we treat these age-related transfers separately since they have different dynamics - pension transfers are expected to be controlled by the government's macro indexing, while health transfers are projected to evolve along with aging. After the transition period, per capita pension and health transfers are assumed to grow at the rate of 1 percent in line with per capita GDP growth.

In the model economy, pension transfers are categorized into two types: basic pension; and employees' pension. Per capita basic pension at initial period is assumed to be the same amount for all retirees over 65 years old, regardless of their productivity. On the other hand, per capita employees' pension is linked with lifetime labor income described above. At initial period, per capita transfers are calibrated to match the aggregate benefit in 2015. Under the current Japanese pension system, in principle, both basic and employees' pension transfers for those aged 65-67 are set to increase along with real wage growth. At the same time, transfers are also adjusted following the macroindexing mechanism with the aim of containing the growth of aggregate pension transfers in percent of GDP. In the model, real wage growth can be proxied by labor-augmenting technology growth of 1 percent. Hence, in terms of the size of macro-indexing adjustment and adjustment period, we follow one of the authorities scenario in the 2014 Actuarial Valuation (published by the Ministry of Health, Labor and Welfare) with real wage growth of 1 percent ("Scenario G"). ${ }^{7}$ Henceforth, we will refer to the above adjustments to pension payments simply as the "macroeconomic slide" in model simulations.

\footnotetext{
${ }^{7}$ See Appendix for details.
} 
Then, the trajectory of per capita pension transfers can be described as:

$$
T_{t+1}^{j, k, p}=T_{t}^{j-1, b}(1+\gamma) M_{t}^{b}+T_{t}^{j-1, k, e}(1+\gamma) M_{t}^{e}
$$

for $j=65, \ldots, 67$, where $T_{t}^{j, b}$ and $T_{t}^{j, e}$ are basic and employees' pension benefits respectively, while $M_{t}$ is the macro-indexing adjustment factor. On the other hand, for $j=68, \ldots$

$$
T_{t+1}^{j, k, p}=\max \left(T_{t}^{j-1, b} M_{t}^{b}, 0.8 T_{t+1}^{65, b}\right)+\max \left(T_{t}^{j-1, k, e} M_{t}^{e}, 0.8 T_{t+1}^{65, k, e}\right)
$$

Pension benefits for those aged 68 or above are no longer adjusted along with real wage growth. But, with the aim of preserving the equity among retirees, the lower bound of benefit is set to 80 percent of the benefit for those aged 65 .

Figure 6 shows age-specific per capita health transfers and effective copayment rates in real terms at initial period. This is estimated based on per capita spending for health and long-term care and effective copayment rates in FY2015 published by the MHLW. Health transfers for those aged 65 or above is about 6.8 times higher as those aged 18-64. Moreover, transfers for aged 85 or above are 4.4 times high relative to those for aged 65-69. The elderly also benefit from low copayment rates. Per capita health transfers are assumed to evolve at the rate of long run per-capita GDP growth (1 percent) plus excess cost growth of 0.7 percent over 30 years. ${ }^{8}$

\section{Evaluation of Alternative Financing Options}

Next, we turn to our policy experiments. ${ }^{9}$ Our baseline will be the case where the debt-to-GDP ratio is stabilized at its current level of 2 times GDP, and consumption taxes (labelled as "VAT" in the figures) adjust to satisfy the government constraint. Because the number of workers per retiree is falling, and because spending per capita increases exponentially with age, the resulting sequence

\footnotetext{
${ }^{8}$ Excess cost growth rate of 0.7 percent is in line with the ex-post excess cost growth over past 5 years. This assumption could overestimate the excess cost growth in the model as ex-post excess cost growth could turn out to be higher than 0.7 percent due to the negative impact of fiscal adjustments on the economy.

${ }^{9}$ McGrattan and Prescott (2016) provide details of the algorithm used to compute equilibria, the only modification required for the version of the model used here is an external loop that computes the equilibrium portfolio composition of the economy, given a debt to GDP target.
} 
of consumption tax increases over time. We then consider other policy packages that finance the costs of aging (at least partly) in different ways. In all cases, consumption taxes will adjust period by period, to guarantee the government budget constraint is satisfied.

To compute the transition paths and welfare consequences for alternative policy reforms, we hold fixed over time the ratios of government consumption (excluding agings costs) to GDP, and the fraction of the population with a particular productivity type. The initial state is summarized by the level of government debt and the distribution of household asset holdings. The initial distribution of ages is determined so that the model matches Japan in 2015. We then use Japan's demographic projections and feed into the model the forecast growth rate of the 18 year old population over time, as well as forecast values for age-specific survival probabilities. At time $t=0$ households learn about the policy packages that will be used to finance the transition, and we determine the welfare consequences for people of all ages and productivity levels that are alive, and for all new cohorts entering the workforce in future years.

\subsection{Baseline: Financing the Costs of Aging through Consumption Taxes}

The first transition path that we compute as our baseline assumes the debt-to-GDP ratio is stabilized at its current level, and adjusts consumption taxes, and only consumption taxes, to finance the changing costs of retirement, long-term and health care (what we call the costs of aging) as the population ages. The consumption tax rate required to finance the costs of aging rises from a baseline rate of 8 percent to about 20 percent. The net tax schedules for workers and retirees are not changed, but revenues and transfers change in response to the demographic transition.

Figures 6-9 summarize the key trends that emerge in this economy. Aging costs are the sum of pension transfers, plus health and long term care costs. Total aging costs (Figure 6) go up slowly from 18 percent of GDP and peak at about 24 percent of GDP by 2057. The impact of the "macroeconomic slide" resulting from the recent pension reform in Japan (embedded in our calculations) is reflected in the fact that most of the increase in aging costs is driven by increases in health spending, up to 2030. Demographic changes eventually dominate and by 2057 pensions and health contribute about equally to expected government outlays on aging costs (the latter is consistent with Imrohoroglu, Kitao and Yamada (2016)).

Financing the costs of aging exclusively through consumption taxes require continuous, but 
very gradual, increases in the consumption tax rate (see Figure 7 for VAT(baseline)). Half of the required adjustment (the consumption tax rate reaching 14 percent) occurs by 2030 .

Demographics and the needed fiscal adjustment exert an important influence on GDP (Figure 8) and other key macroeconomic variables. Because of the shrinking population and the continuous increases in the dependency ratio, GDP is only 5 percent higher in 2040 than it is today (see Figure 8 for GDP(baseline)). If the labor force remained constant, given the underlying 1 percent growth in total factor productivity, GDP would be 30 percent higher by 2040. Hours worked per person go down, which reduces the marginal product of capital. Because this is a closed economy, this translates into lower rates interest rates, and a lower investment-to-GDP ratio. Private consumption to GDP goes up (even excluding health and long term care consumption).

Labor income tax and business tax revenues (as shares of GDP) are essentially unchanged with the demographic transition (Figure 9). Current workers know taxes will increase and incomes will decrease and respond by increasing their labor supply, preventing labor income taxes from falling faster than GDP.

\subsection{Increasing Social Security Contributions}

Under the current health and long-term care system, about half of total spending is financed through social security contributions, which will be adjusted across all income brackets. To analyze the implications of increases in personal contributions, it is assumed that the rate of labor income tax is gradually increased by 8 percentage points over 20 years (Figure 10). This scenario is labelled as "SSC" in the figures. This increase is what is required to finance expected increases in the cost of aging that are due to health spending. The first important result is that in consumption taxes still need to increase gradually, but continuously, by up to 8 percentage points if debt to GDP is going to remain stable (see Figure 8 for GDP(SSC)). This is roughly half of the increase necessary under the preferred policy scenario. Second, increasing social security contributions raises the effective labor income tax rate. Progressive labor income tax rates are well known to be more distortive than consumption taxes on the macroeconomy. ${ }^{10}$ After 25 years, GDP is about 4 percent lower than under the preferred policy, and the difference becomes as large as 7 percent in a longer horizon (see

\footnotetext{
${ }^{10}$ Both the consumption tax and labor income tax incentivize workers to reduce hours worked and increase hours for leisure. However, consumption taxes have a flat rate and are imposed on a broader base including retirees.
} 
Figure 8 for GDP(SSC)). Interestingly, in the short run, GDP differences are barely noticeable. This happens because young workers know they will face higher future income taxes, and respond by increasing their labor supply in the short run, and also by saving more.

In terms of welfare (Figure 11), retirees and older workers gain since they care mostly about consumption, and this policy scenario allows consumption taxes to remain lower than in the preferred policy case. However, young workers and all generations thereafter suffer very large losses averaging about 5 percent of lifetime welfare. Labor income taxes are progressive and thus higher personal contributions have a more negative effect on higher income individuals. The top 1 percent of earners on average lose about 8 percent of life-time welfare, while the bottom 30 percent loses close to 4 percent.

\subsection{Debt Financing}

To analyze the costs of delaying adjustment, continuous deficit financing (and debt accumulation) is assumed and debt is stabilized after 2040 (the resulting debt-to-GDP ratio is 3, see Figure 12). This scenario is labelled "debt" in the figures. The interest rate on government debt is assumed to remain unchanged at 1 percent in real terms. Stabilizing debt under this scenario requires even higher future consumption tax rates to finance the government budget, peaking at about 29 percent (see Figure 7 for VAT(debt)).

In equilibrium, this policy causes large crowding out of private sector investment (Figure 14). The reason is that households must be compelled to save enough to hold a much larger stock of government debt, and this can only happen by increasing the cost of capital for the private sector

(Figure 13). The macroeconomic cost of delaying adjustment, due to the crowding out effects, are large and quickly set in. Indeed, after 10 years GDP is 4 percent lower than in the preferred policy scenario, but more than 15 percent lower after 20 years (see Figure 8 for GDP(debt)).

In terms of welfare (Figure 15), delaying adjustment is very costly. Most individuals lose from this strategy. Older individuals could benefit from lower consumption taxes. However, lower aggregate growth due to the crowding out effect outweighs the potential benefits for the most elderly. Losses are in excess of 16 percent of life-time welfare, on average. 


\subsection{Increasing Health Copayment Rates}

Under the current system, adults between 20 and 64 years old pay on average an effective copayment rate on health expenditures of 17.3 percent, while adults aged 65 and older pay an average effective copayment rate of 9.5 percent (the rate is 15.3 percent for those between 65 and $69,9.3$ percent for those between 70 and 74, and about 8.5 percent for older individuals). Here, we consider a scenario where health copayments for those aged 65 and older are increased to the average level paid by those between 20 and 64 year of age. We do this gradually (at a constant rate of increase), over a 20 year period. The effects of this change result in a permanent reduction in the net health and long term transfers of about 8 percentage points, for those in the relevant groups. As in the baseline, we assume the debt-to-GDP ratio remains constant, and adjust only consumption taxes to guarantee the government budget constraint is satisfied every period.

This option could help mitigate tax increases for future generations who are expected to be most affected by the effects of demographic transition. On the other hand, net health transfers do not vary much (conditional on age) by income levels. Hence, an increase in copayments rate of equal magnitude across the income spectrum should be regressive. Indeed, we find that the bottom third of the population would experience large welfare losses under this policy, as large as 6 percent of life-time utility. Most (the bottom 99 percent, in terms of income) of the population currently between 18 and 90 years old would experience welfare losses (Figure 16), with disproportionate negative effects on young and lower income workers.

The relatively large welfare losses for the bottom third of the income distribution highlight the importance of due consideration in safe-guards for low-income households in this kind of reform. Moreover, this policy alone yields only modest gains in terms of the needed fiscal adjustment. Consumption taxes still increase gradually, but substantially, peaking at a rate of about 17 percent.

\section{Evaluation of Other Reform Options}

This section considers the sensitivity of the model, and on our estimates of government financing needs, to more favorable assumptions on demographic trends, improvements in the efficiency of the health sector, and improvements in economy wide productivity. While our findings suggest none of these options alone can fully address Japan's aging costs, they can be useful complements 
to the preferred policy option of gradually increasing consumption taxes. Our results highlight the importance of a policy package including both a government financing plan that minimizes distortions on the economy, as well as broader reforms.

\subsection{Alternative Demographic Pattern with Higher Fertility Rate}

The IPSS presents a range of possible scenarios for long run trends in fertility and mortality. As described in Section 4, the above experiments are based on the IPSS' medium fertility rate and medium mortality rate scenario. Here, we study the sensitivity of our results to alternatives. For this, we employ what the IPSS considers a favorable demographic scenario of a high fertility rate (involving a gradual improvement by the mid-2020s to the range of 1.6-1.7 live births per woman in her lifetime) and medium mortality. This scenario is labeled "demographics" in the figures. Baseline and favorable scenarios imply very similar patterns for population dynamics in the medium term (up to 2030). The favorable scenario embeds an important recovery of the growth rate of population entering the workforce in the mid 2030s, and implies a long run growth rate for the population of -0.85 percent (instead of -1 percent in the baseline). Because of the macro-indexing mechanism in Japan's pension system, different demographics also imply different future flows of pension transfers. The 2014 Actuarial Valuation provides estimates for the implied changes, which we introduce in our simulations.

Figure 17 and 18 summarize the results. Since demographic trends are essentially the same until 2030 under the two scenarios, and since the impact of population changes permeates slowly through the economic system, the differences in the VAT rates required under this alternative demographic scenario are not very noticeable before 2040. By 2065 the difference becomes more material as the required consumption tax to keep debt-to-GDP ratio constant is about 3 percentage points lower than in the baseline. A more noticeable impact occurs on GDP, which by 2065 is 8 percent higher under the favorable demographic scenario than in the baseline. This difference is mostly due to the fact that in the long run the growth rate of TFP under the two scenarios is assumed to be the same, but population shrinks at a slower pace in the new scenario. Since GDP growth in the long run is the product of the change of TFP growth and population growth, larger GDP naturally takes place. 


\subsection{Improving Efficiency of Health Services}

Miake, Nozaki and Schneider (2018) evaluate options for healthcare system reform. Their findings suggest that improvements in the efficiency of the healthcare system could potentially yield a reduction in total health spending by up to 10 percent (that materialize gradually but remain into the future). Because the savings are derived through improvements in efficiency, the expected impact on the quality of services is assumed to be negligible. We thus allow for the costs of savings to decline continuously over a 12 year period, but assume the real consumption of health services is unchanged. This scenario is labelled "health efficiency" in the figures. Under these assumptions, and under the baseline demographic projections, the required increases in consumption taxes are smaller than in the baseline (Figure 17). Quantitatively, the impact is noticeable, reaching a maximum and essentially permanent reduction of more than 2 percentage points in the consumption taxes required to stabilize the debt. The effects on GDP are positive but moderate (Figure 18).

\subsection{Improving Economy Wide Productivity}

We conclude this section by considering the implications of faster productivity growth. In principle, faster growth could provide an opportunity to contain government expenditures as a share of GDP. In the case of Japan, however, some expenditures are naturally linked to growth. Expenditure on the pension system, for example, is determined by a government formula linked directly to the growth rate of the economy (see Appendix on pension transfers). Furthermore, the number of periods over which the "macroeconomic slide" operates, and thus pension payments grow at a rate lower than GDP, decreases as economic growth improves. Hence, faster growth does not necessarily reduce government pension outlays as ratios to GDP.

As the effects of faster growth on overall financing needs are difficult to sort out, we consider two alternative scenarios. Both scenarios assume a permanent acceleration of TFP growth from 1.0 percent (as assumed in the baseline) to 1.5 percent. This size of TFP improvement is within the range of effects that credible structural reforms (including labor market reforms, product market

reforms, as well as opening further to international trade) could bring to Japan, according to previous IMF work (see Colacelli and Fernandez-Corugedo, 2018). Both scenarios also assume that consumption taxes are the only tax that adjusts to ensure that the debt-to-GDP ratio remains 
constant, and assume that government outlays on pensions are dictated by the spending rules of the Japanese pension system.

In the first scenario, we assume government consumption (which excludes pensions, health and long term care) grows at par with GDP, while per person health and long term care government outlays grow at 1.7 percent per year for 20 years (as in the baseline case of earlier sections). This scenario is labelled "TFP" in the figures. The second scenario instead assumes that both government consumption spending and government outlays on health and long term care grow at 1 percent (the long-run growth rate of all scenarios prior to this section) for 20 years. This scenario is labelled "TFP, GC and health grow at 1 pct" in the figures.

Figures 19 and 20 summarize the results. A key observation is that faster TFP growth has very positive implications for levels of GDP, as should be expected. Under both scenarios, the level of GDP increases by about 17 percent by 2047 and keeps rising to reach a level 23 percent larger than 2017 output by 2067 (Figure 19). In terms of the financing needs of the government, under the first scenario we find that the reduction in fiscal adjustment generated by faster productivity growth is very modest. It peaks at a temporary 2 percentage point reduction in the consumption tax rate by the mid-2030s, and yields a less than 1 percentage point reduction in the rate in the long run. The reasoning behind this is that the gains from faster growth in reducing the health costs-to-GDP ratio are compensated by the reduction in years of the macroeconomic slide. In sharp contrast, in the second scenario where growth in government consumption and outlays in health and long term care are contained, substantial savings are realized. The reduced financing needs peak at about a 5 percentage point reduction in the consumption tax rate by the mid-2030s, and stay at about that level in the long run. In this case, the consumption tax rate still needs to rise, but peaks at a more modest 15 percent rate (Figure 20).

\section{Conclusions}

A challenging economic policy issue facing Japan and many other nations is the financing of retirement and other age-related government spending as the population ages and the number of workers per retiree declines. We find that the fall in the number of workers per retiree requires major fiscal adjustments, which can nevertheless be done at a gradual pace. Different ways of performing the 
fiscal adjustment have dramatically different effects on welfare. We find that among the policy options, a continuous and gradual adjustment of consumption taxes dominates all of increasing the social security contributions, delaying adjustment (with an implied prolonged period of debt financing), and increased health copayment rates, by having a relatively smaller adverse effect on long-run GDP and welfare. Financing higher health costs through increases in labor income tax rates is highly distortive and results in an 7 percent lower long-run GDP and significantly lower welfare for young workers and future generations. Postponing adjustment through debt financing results in a large crowding out of private sector investment - by up to 8 percent - with detrimental effects on long-run GDP and welfare. Finally, a uniform increase in health copayment rates for the elderly implies shifting a part of aging costs to current generations, but with regressive consequences. More benign demographic patterns improve the long run outlook slightly, while expected efficiency gains in the health sector reduce the required increase in consumption taxes by more than 2 percentage points. Comparable savings can be attained with reforms that improve overall productivity growth, but only when government outlays are also contained. There is certainly an intergenerational tension across policies, as increasing social security contributions or delaying adjustment benefit current retirees and old workers at the expense of all future generations. 
Table 1. Adjusted National Income and Product Accounts for 2015

\begin{tabular}{|c|c|}
\hline Total adjusted income & 1.000 \\
\hline Labor income & 0.530 \\
\hline Compensation of employees & 0.513 \\
\hline Wages and salaries & 0.436 \\
\hline Employers' social contributions & 0.077 \\
\hline Households business (70 percent labor income) & 0.017 \\
\hline Capital income & 0.470 \\
\hline Corporate profits & 0.134 \\
\hline Households business (30 percent labor income) & 0.007 \\
\hline Households operating surplus & 0.051 \\
\hline Taxes on production and imports & 0.088 \\
\hline Less: Consumption tax & 0.042 \\
\hline Less: subsidies & 0.006 \\
\hline Consumption of fixed capital & 0.235 \\
\hline Statistic discrepancy & 0.003 \\
\hline Total adjusted product & 1.000 \\
\hline Consumption & 0.754 \\
\hline Private consumption & 0.675 \\
\hline Less: consumption tax & 0.042 \\
\hline Government consumption & 0.121 \\
\hline Investment & 0.246 \\
\hline Gross private investment & 0.209 \\
\hline ow corporations & 0.172 \\
\hline ow households and NPO & 0.037 \\
\hline Gross government investment & 0.039 \\
\hline Changes in inventories & 0.002 \\
\hline Net exports & -0.004 \\
\hline
\end{tabular}


Table 2. Adjusted fixed asset tables with stocks end of period for 2015

\begin{tabular}{|lc|}
\hline Tangible capital & 5.386 \\
Fixed assets & 3.130 \\
Corporates & 1.331 \\
Households and NPOs & 0.715 \\
Government & 1.084 \\
Land & 2.256 \\
Intangible capital & 0.273 \\
Corporates & 0.227 \\
Households and NPOs & 0.014 \\
Government & 0.032 \\
Total & 5.659 \\
\hline \hline Sources: Cabinet Office and IMF staff estimates. \\
\hline
\end{tabular}


Table 3. Parameters of the model economy calibrated to Japan's data

\begin{tabular}{|c|c|}
\hline \multicolumn{2}{|l|}{ Demographics } \\
\hline Population growth rate & -1 \\
\hline Maximum work life in years & 63 \\
\hline \multicolumn{2}{|l|}{ Preferences } \\
\hline Disutility of work $(\alpha)$ & 2.2 \\
\hline Discount factor $(\beta)$ & 0.986 \\
\hline Government consumption & $0.115 \mathrm{GDP}$ \\
\hline \multicolumn{2}{|l|}{ Technology } \\
\hline Growth rate of TFP & 1 percent \\
\hline Income share of corporates & 0.5 \\
\hline \multicolumn{2}{|l|}{ Capital shares } \\
\hline Tangible, corporate $\left(\theta_{1 T}\right)$ & 0.45 \\
\hline Intangible, corporate $\left(\theta_{1 I}\right)$ & 0.15 \\
\hline Tangible, household bus. $\left(\theta_{2 T}\right)$ & 0.35 \\
\hline Intangible, household bus. $\left(\theta_{2 I}\right)$ & 0.05 \\
\hline \multicolumn{2}{|l|}{ Fiscal } \\
\hline Government debt & 2.0 \\
\hline Corporate income tax & 25 percent \\
\hline Tax on corporate distributions & 25 percent \\
\hline Tax on household bus. distributions & 29 percent \\
\hline
\end{tabular}


Table 4: Tax rates and and incomes (amounts are in $¥$ millions for average earnings and $¥$ trillions for aggregate)

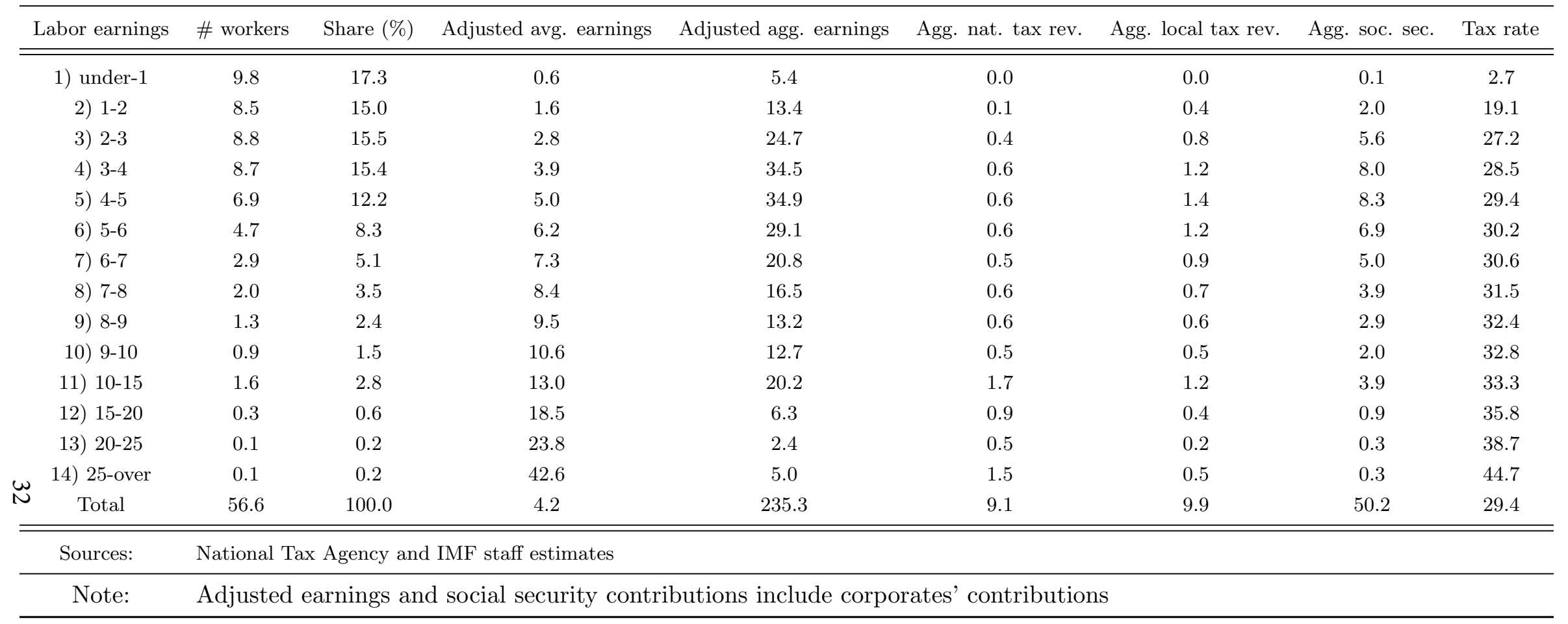


Figure 1. Old-age Dependency Ratios, Japan and The Next 10 Highest OECD Countries

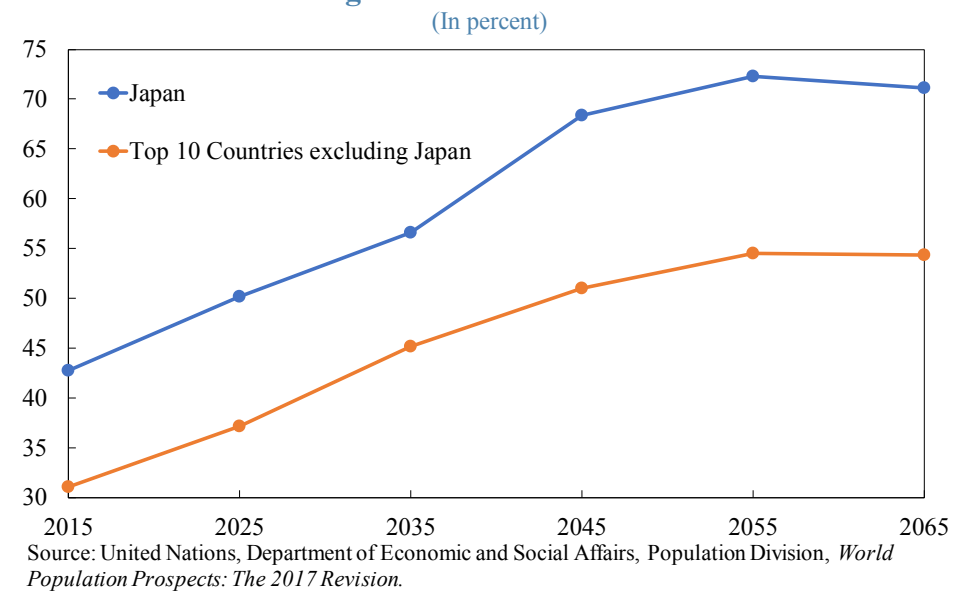

Figure 2. Old-age Related Spending, Japan and OECD Countries

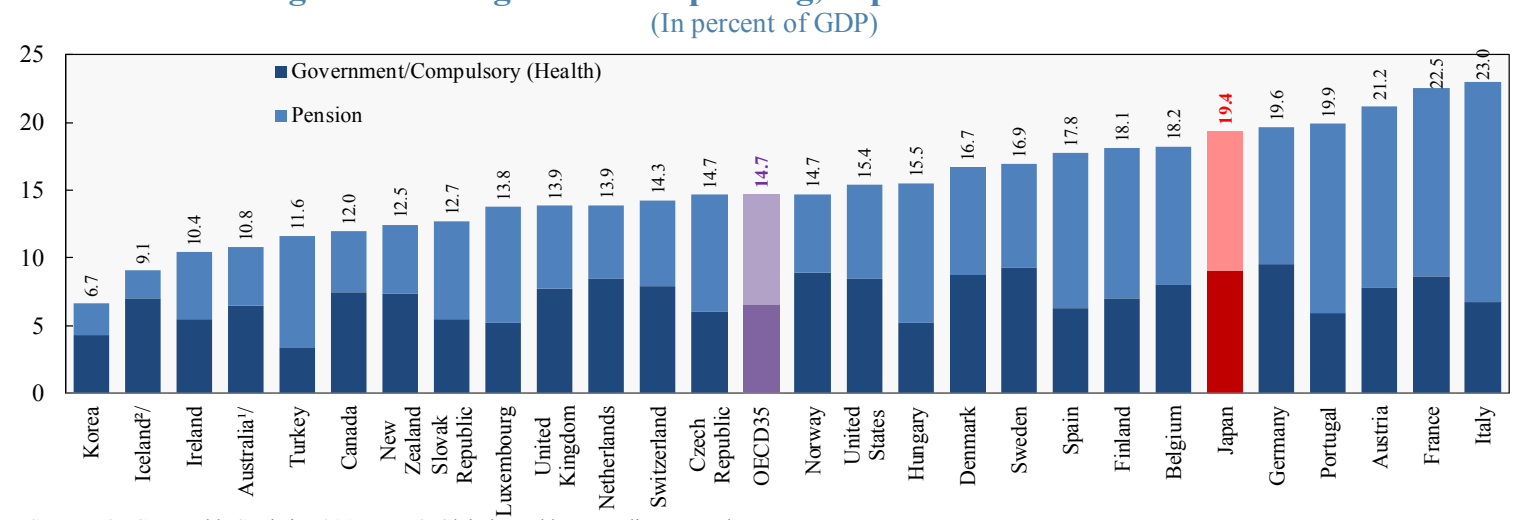

Source: OECD Health Statistics 2017, WHO Global Health Expenditure Database.

$1 /$ Australian expenditure estimates exclude all expenditure for residential aged care facilities in welfare (social) services.

2/ Includes investments.

Figure 3. OECD Countries: Tax Revenues to GDP

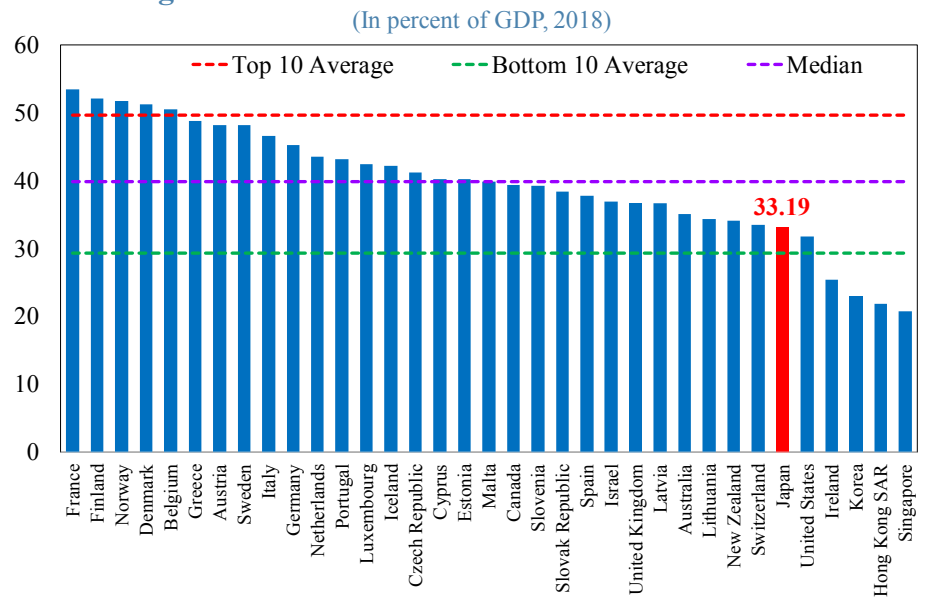

Source: OECD, Tax Statistics. 
Figure 4. Japan: Health Transfers and Copayments by Age (In constant $¥$, thousand)

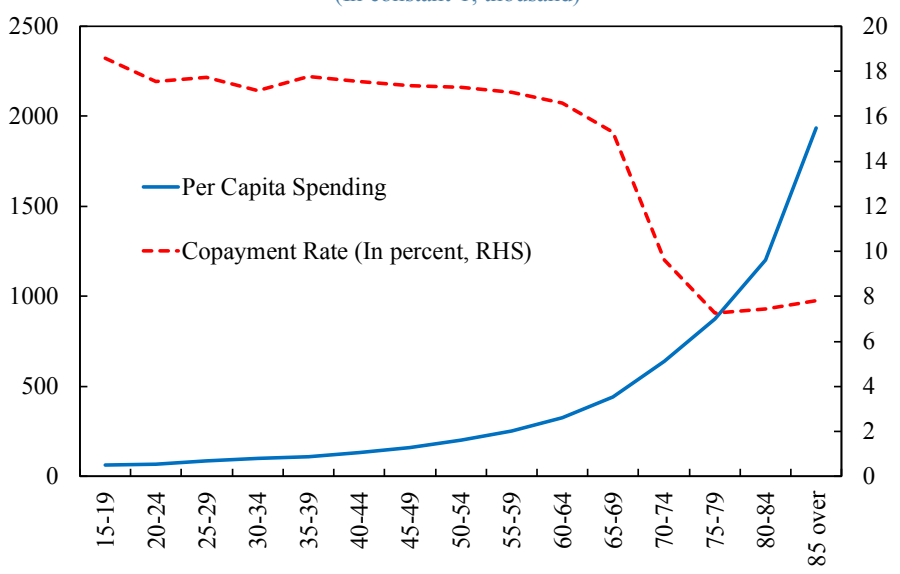

Sources: Ministry of Health, Labor, and Welfare; IMF staff estimates.

Figure 5. Earning Patterns by Productivity Type and Age Labor Income Across Age (Normalized, Mean Income =1)

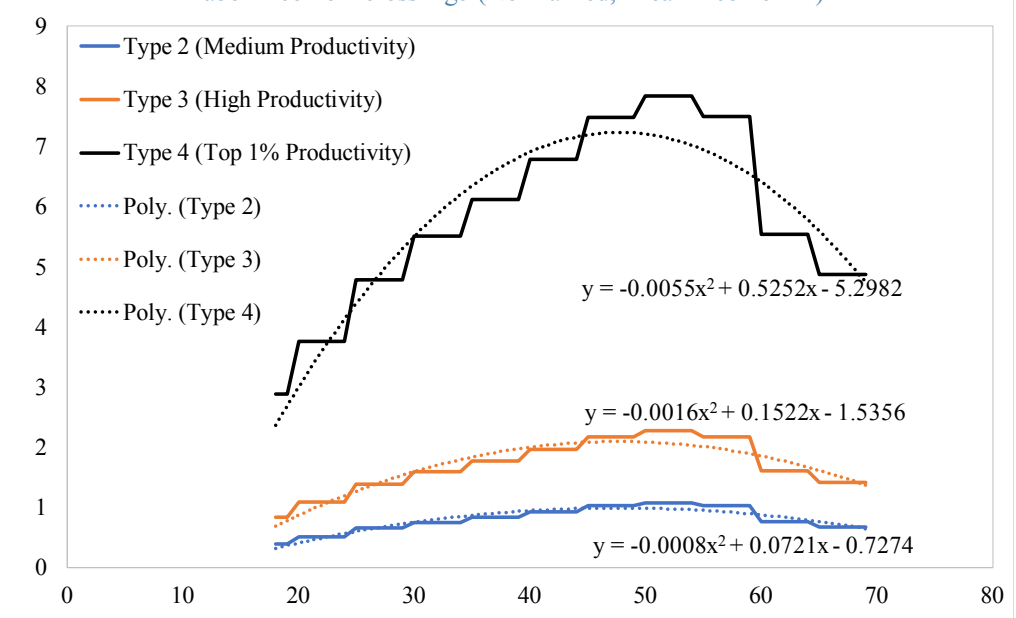

Sources: Basic Survey on Wage Structure; Ministry of Health, Labour and Welfare; IMF staff calculations.

Figure 6. Aging Costs: Total and Health plus Long-term Care Total Transfers and Health Transfers - Baseline Scenario (In percent of GDP)

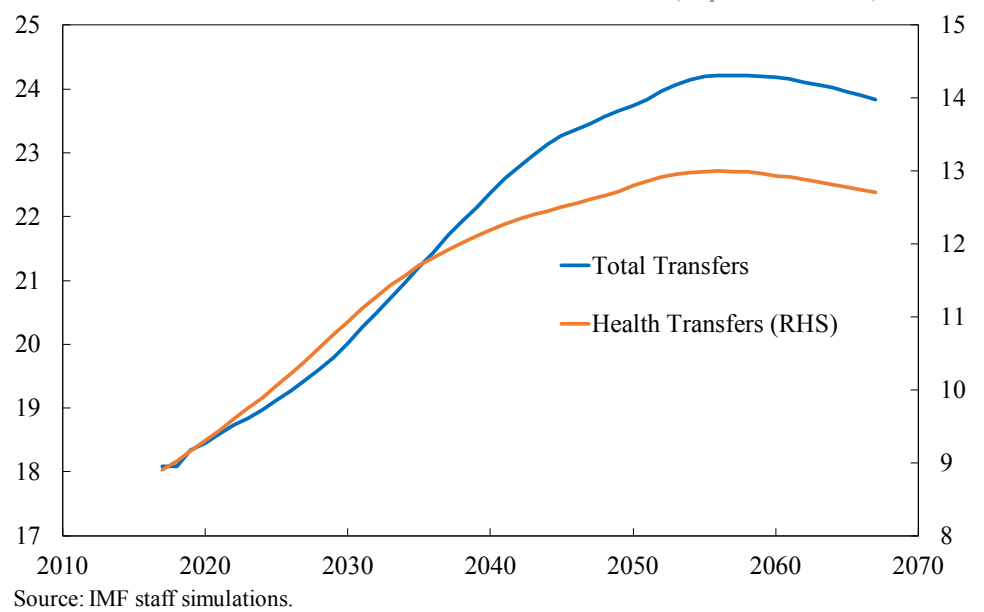


Figure 7. Consumption Taxes Under Different Scenarios

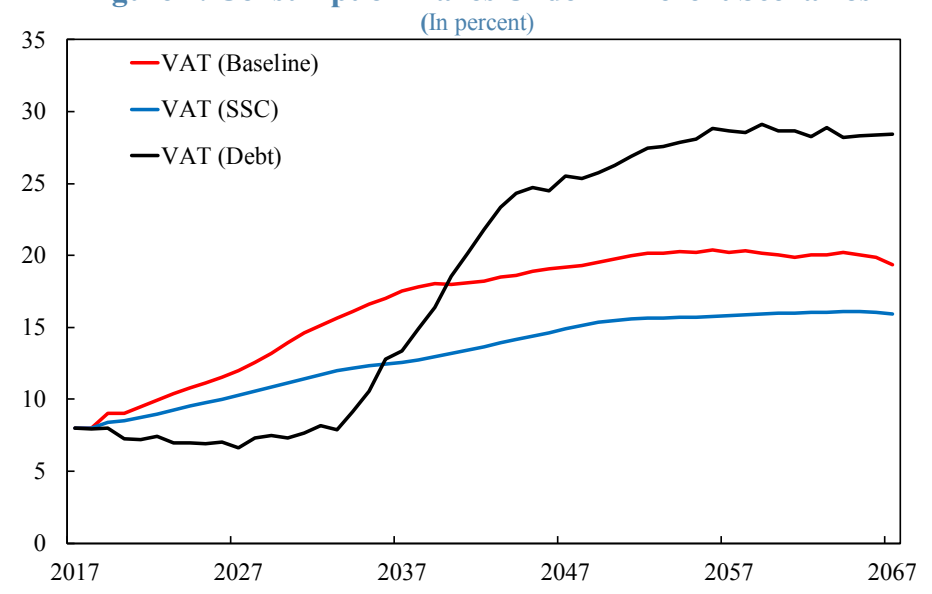

Source: IMF staff simulations.

Figure 8. GDP Under Different Scenarios (Index, 2018=100)

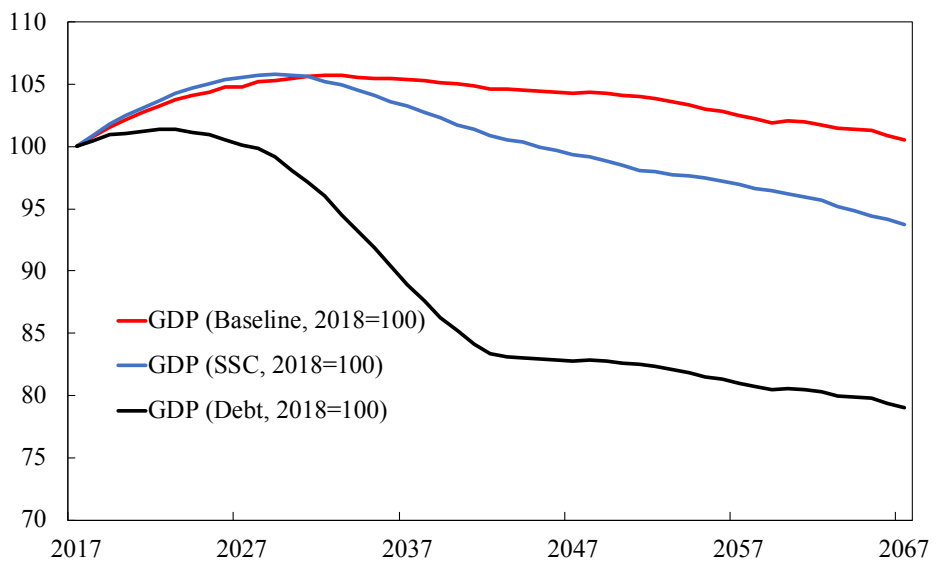

Source: IMF staff simulations.

Figure 9. Sources of Government Revenue Under the Preferred

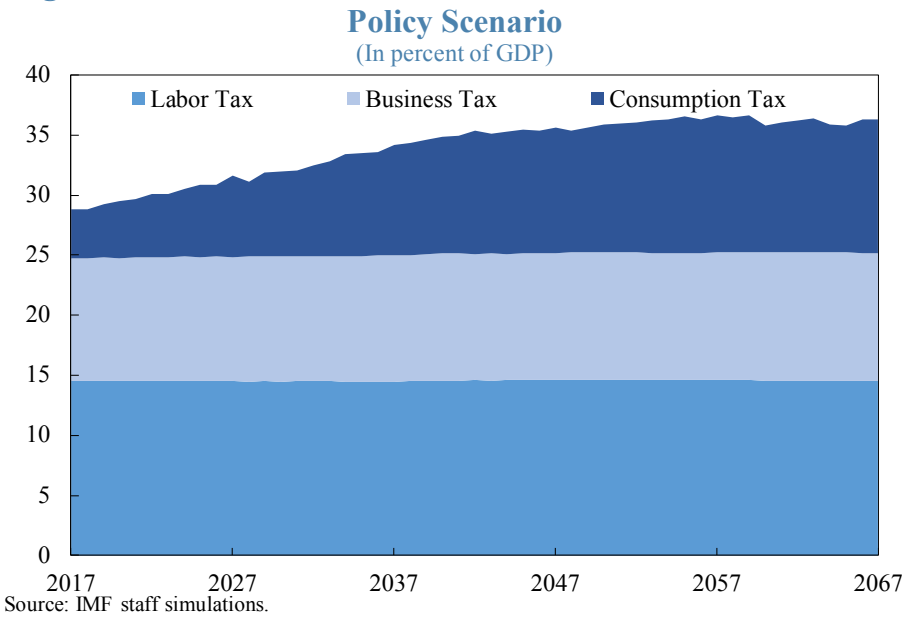


Figure 10. Financing Aging Costs Through Increases in Contributions ${ }^{1 /}$ Change in Personal Income Tax (For All Income Brackets) Change in Contribution Scenario (In percent)

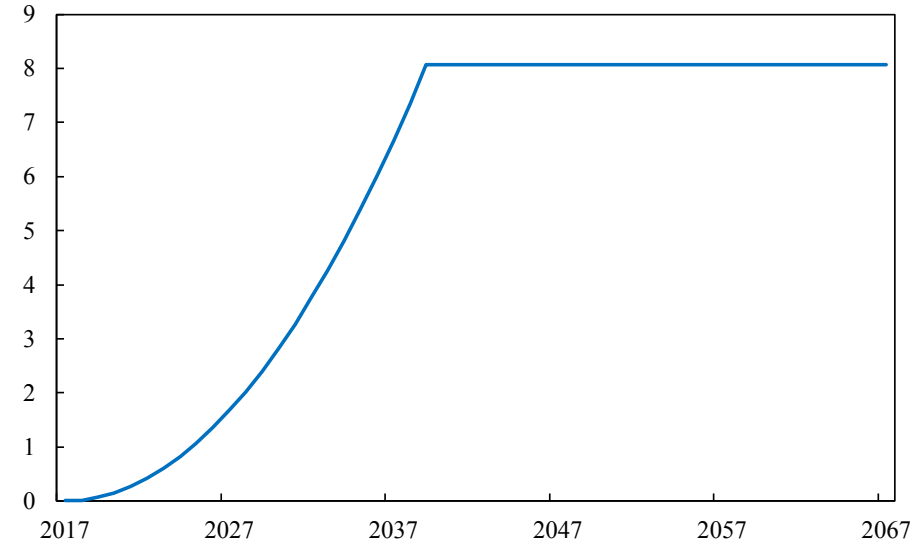

Source: IMF staff simulations.

1 / Note that increased contributions cover higher health and long-term costs.

Figure 11. Welfare Effects of Financing Aging Costs Through Increases in Contributions (Relative to Preferred Policy Scenario)

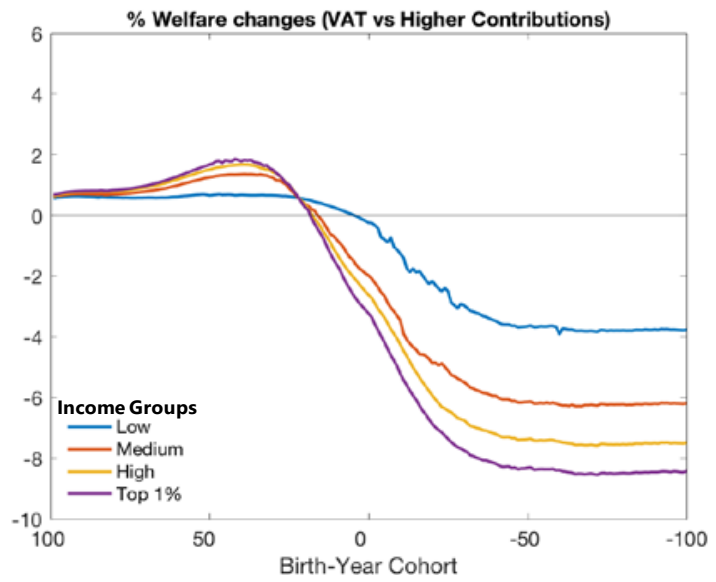

Source: IMF staff simulations.

Figure 12. Debt Financing Scenario Debt-to-GDP Ratio

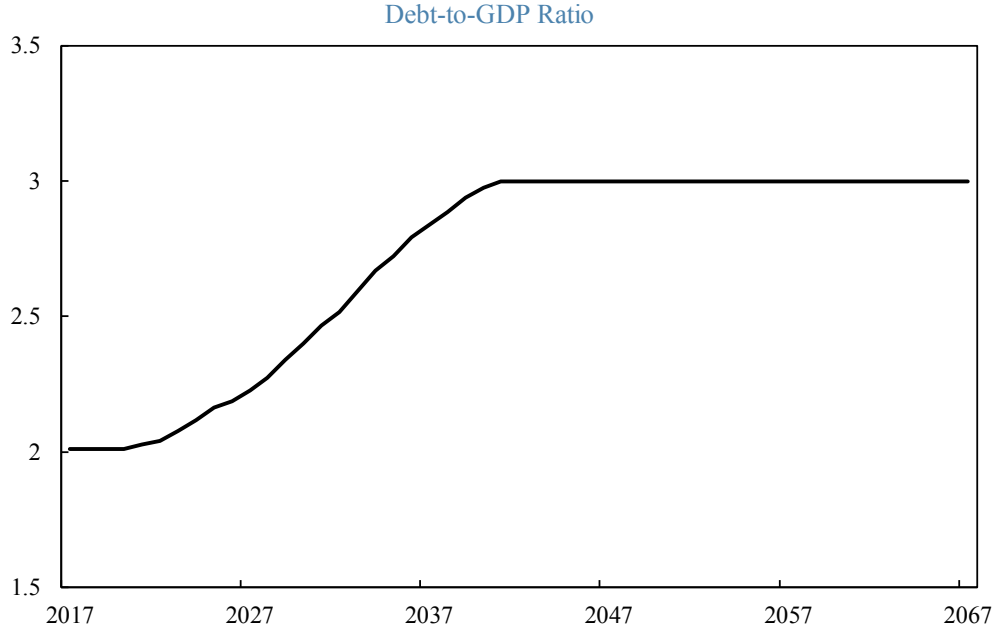

Source: IMF staff simulations. 
Figure 13. Changes in Interest Rates Under Baseline and Debt Financing Scenario

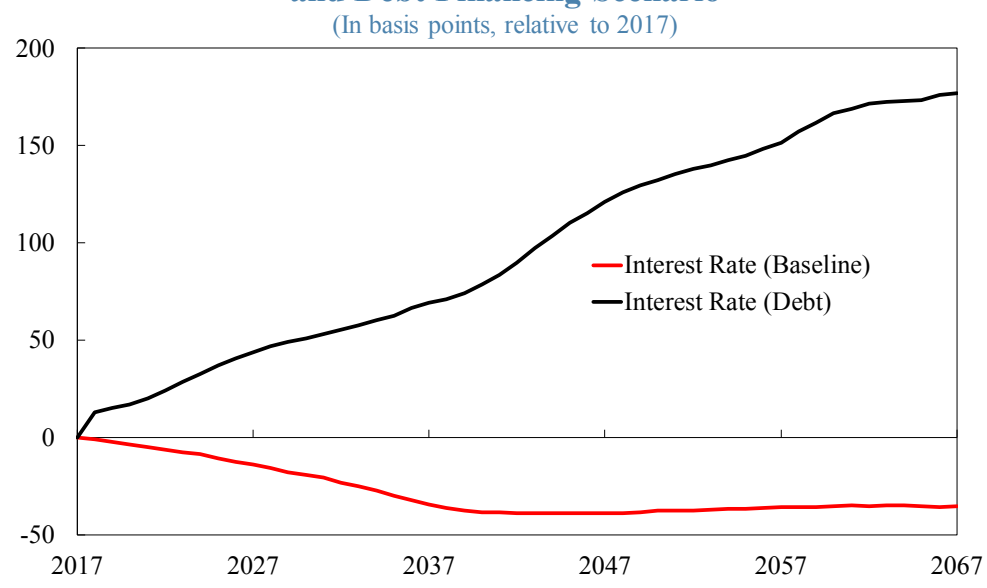

Source: IMF staff simulations.

Figure 14. Crowding Out of Private Sector Investment in Debt Financing Scenario

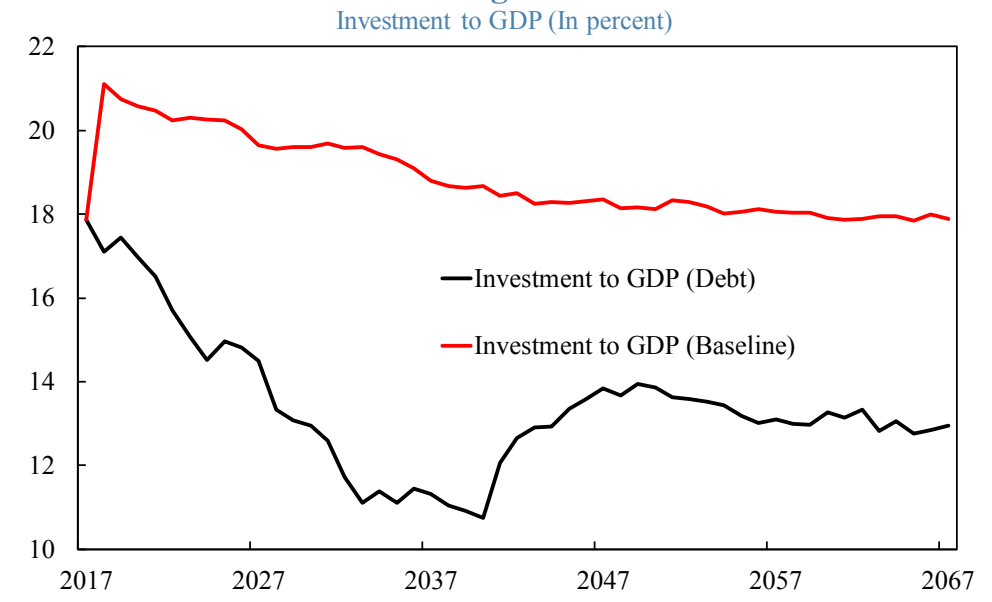

Source: IMF staff simulations.

Figure 15. Welfare Effects of Debt Financing Scenario (Relative to Preferred Policy Scenario)

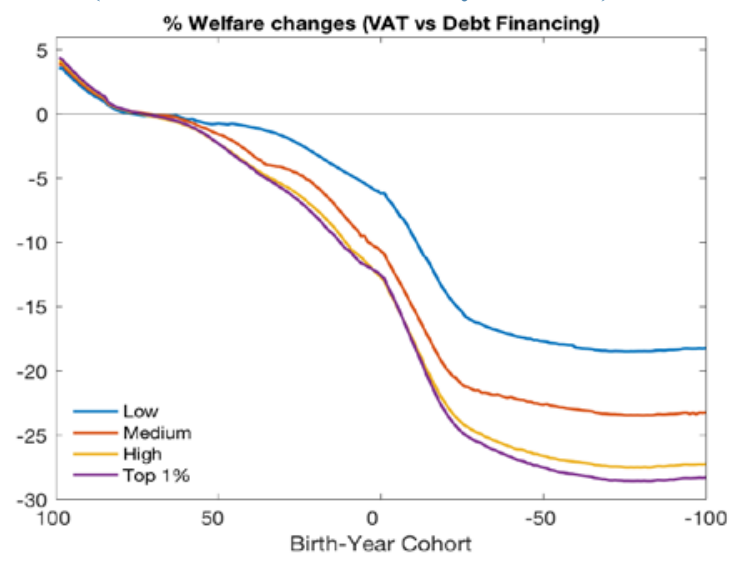

Source: IMF staff simulations. 
Figure 16. Welfare Effects of Increasing Copayment Rates (Relative to Preferred Policy Scenario)

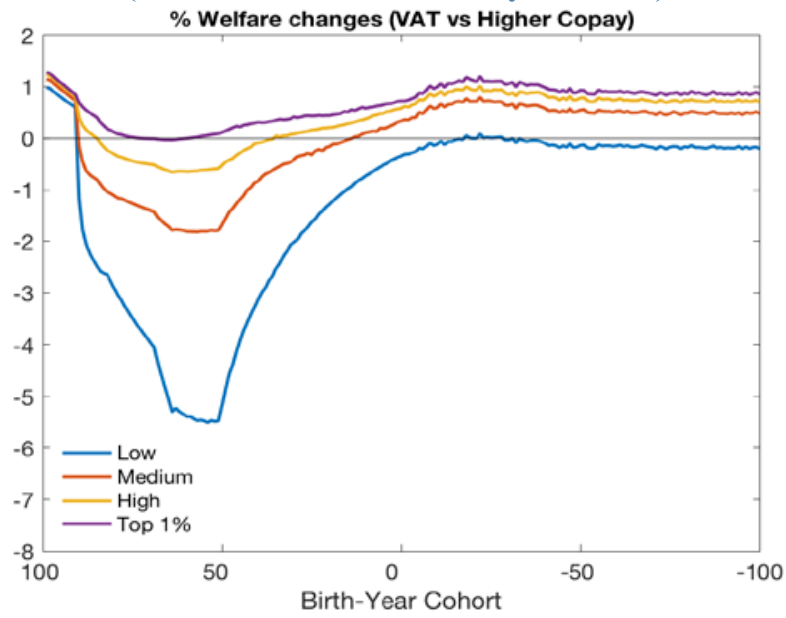

Source: IMF staff simulations.

Figure 17. VAT Adjustment Under Favorable Demographics, or Improved Efficiency in Health Delivery

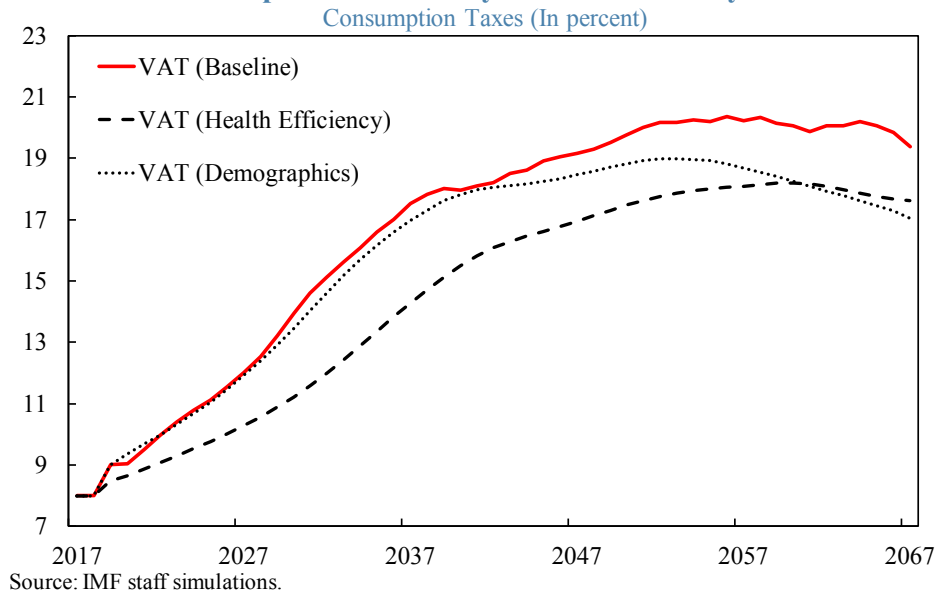

Figure 18. GDP Under Favorable Demographics, or Improved Efficiency in Health Delivery (Index, 2018=100)

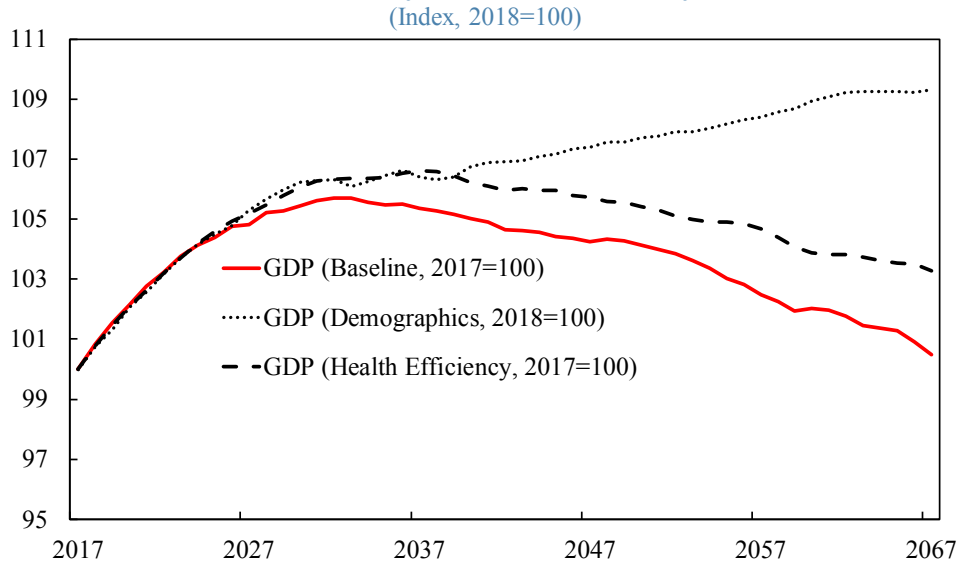

Source: IMF staff simulations. 
Figure 19. GDP when TFP Growth Accelerates (Index, 2018=100)

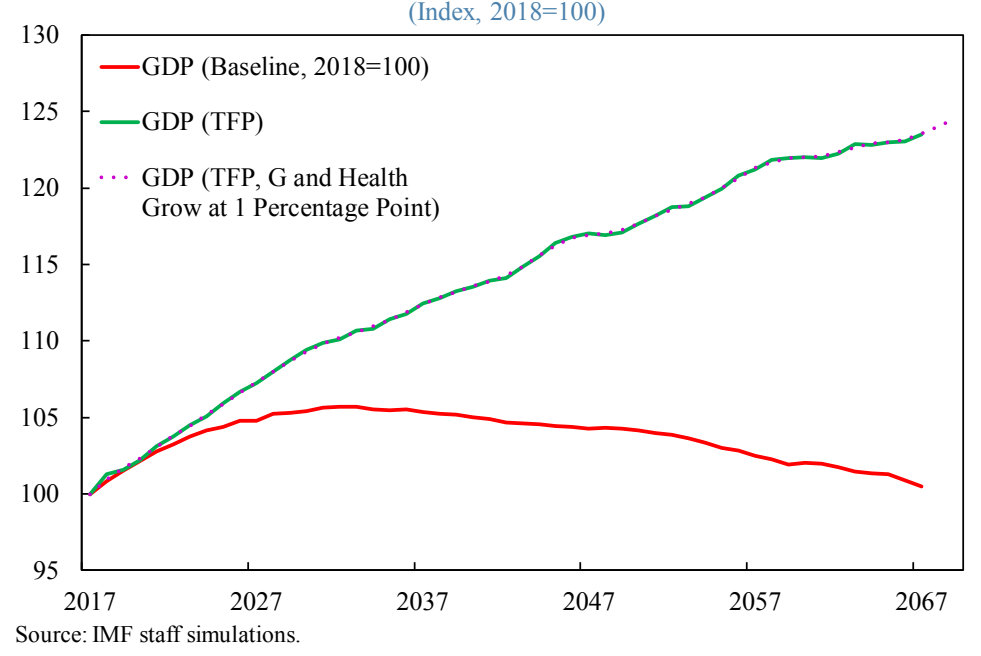

Figure 20. Consumption Taxes When TFP Growth Accelerates

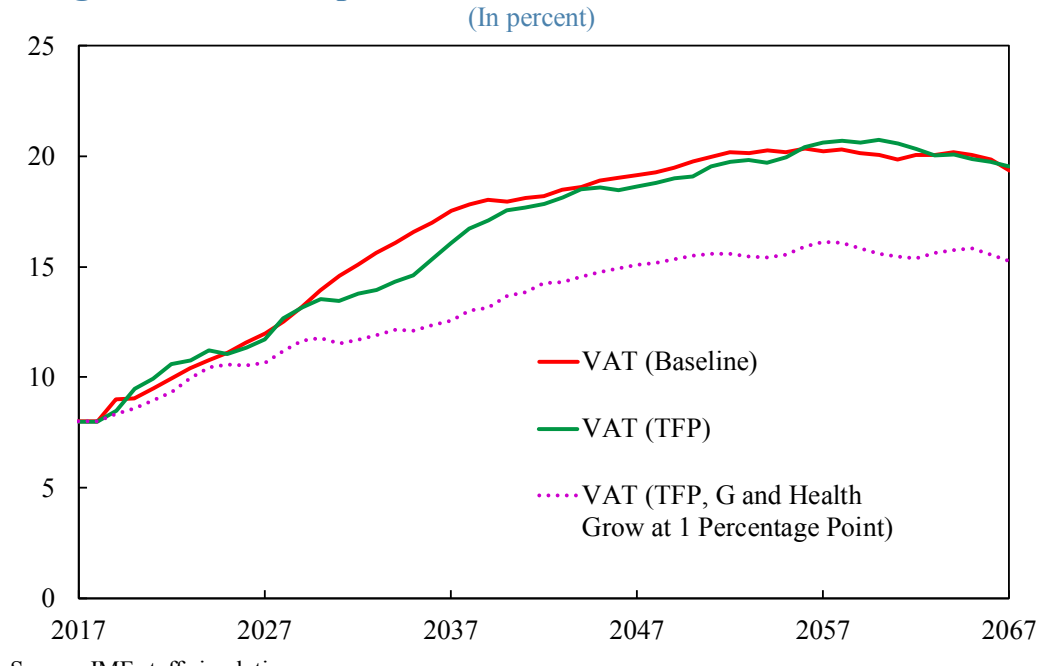

Source: IMF staff simulations. 


\section{References}

Arato, Hiroki, and Katsunori Yamada, "Japan's Intangible Capital and Valuation of Corporations in a Neoclassical Framework," Review of Economic Dynamics, Vol. 15 (2012), pp. 459-78.

Braun, Anton, and Douglas H. Joines, "The Implications of a Graying Japan for Government Policy," Journal of Economic Dynamics and Control, Vol. 15(2015), pp. 1-23.

Colacelli, Mariana and Emilio Fernandez-Corugedo, "Macroeconomic Effects of Japan's Demographics: Can Structural Reforms Reverse Them?," IMF Working Paper, (forthcoming).

Conesa, Juan C., and Carlos Garriga, "Optimal Fiscal Policy in the Design of Social Security Reforms," International Economic Review, Vol. 49 (2008), pp. 291-318.

Corrado, Carol, Charles Hulten, and Daniel Sichel, "Intangible Capital and U.S. Economic Growth," Review of Income and Wealth, Vol. 55 (2009), pp. 661-85.

Corrado, Carol, Jonathan Haskel, Cecilia Jona-Lasinio, and Massimiliano Iommi, "Intangible Capital and Growth in Advanced Economies: Measurement Methods and Comparative Results," 2012, IntanInvest (http://www.intan-invest.net).

Feldstein, Martin, ed., Privatizing Social Security (Chicago: University of Chicago Press, 1998).

Imrohoroglu, Selahattin, and Nao Sudo, "Productivity and Fiscal Policy in Japan: Short-Term Forecasts from the Standard Growth Model," Monetary and Economic Studies, (2011), Bank of Japan, pp. 73-106.

Imrohoroglu, Selahattin, and Sagiri Kitao, "Social Security Reforms: Benefit Claiming, Labor Force Participation, and Long-Run Sustainability," American Economic Journal: Macroeconomics 4 (2012), pp. 96-127.

Imrohoroglu, Selahattin, Sagiri Kitao, and Tomoaki Yamada, "Achieving Fiscal Balance in Japan," International Economic Review, Vol. 57 (2016), pp. 117-53.

International Monetary Fund (2010), “Japan: Article IV Consultation Staff Report,” IMF Country Report No. 10/211.

International Monetary Fund (2016), “Japan: Article IV Consultation Staff Report," IMF Country Report No. 16/267.

International Monetary Fund (2017), "Japan: Article IV Consultation Staff Report," IMF Country Report No. 17/242.

Kitao, Sagiri, "Fiscal Cost of Demographic Transition in Japan," Journal of Economic Dynamics and Control, Vol. 54 (2015), pp. 37-58.

McGrattan, Ellen R., and Edward C. Prescott, "On Financing Retirement with an Aging Population," Quantitative Economics, Vol. 8 (2017), pp. 75-115.

McGrattan, Ellen R., and Edward C. Prescott, "Technical Appendix: On Financing Retirement with an Aging Population," Research Department Staff Report 473, Federal Reserve Bank of Minneapolis, 2016.

Miake, Naoko, Masahiro Nozaki, and Todd Schneider, "Japan: Options for Healthcare System Reform,” Japan Selected Issues, 2018 (forthcoming). 
Nozaki, Masahiro, Kenichiro Kashiwase, and Ikuo Saito, "Health Spending in Japan: Macro-fiscal Implications and Reform Options," Journal of the Economics of Aging, Vol. 7 (2017), pp. 156-71.

Organization for Economic Cooperation and Development, (2018), "OECD Health Statistics 2017”, (Paris).

Wallenius, Johanna, "Human Capital Accumulation and the Intertemporal Elasticity of Substitution of Labor: How Large Is the Bias?” Review of Economic Dynamics, Vol. 14 (2011), pp. 577-91. 


\section{Appendix: Assumptions on Pension Transfers}

Under the current Japanese pension system, pension transfers are adjusted for inflation and real wage growth (as explained in Section 4, the latter adjustment only applies to those aged 65-67 years). At the same time, with the aim of containing the growth of aggregate pension spending in percent of GDP, a macro-indexing mechanism was introduced by the government in 2004, which allows for reduced per capita transfers in real terms. The size of annual adjustment reflects the projected decreases in the number on the insured and increases in life expectancy. In reality, the adjustment period depends on the projected trajectory of financial reserves held by pension funds, and therefore has an endogenous nature. For simplicity, however, we follow the assumptions in corresponding scenarios in the 2014 Actuarial Valuation, rather than calculating the size and period of adjustment endogenously. In our model, real wage growth can be proxied by labor augmenting productivity growth of 1 percent for baseline scenario and alternative demographic scenario. ${ }^{11}$ This broadly corresponds to Scenario G in the 2014 Actuarial Valuation (see the table below for key assumptions).

\footnotetext{
${ }^{11}$ Since our model is described in real terms, inflation only matters to the extent that the annual macro-indexing adjustment factor cannot exceed inflation rate for those aged 68 and above.
} 


\begin{tabular}{|c|c|c|c|c||c|}
\hline \multicolumn{6}{|c|}{ Appendix Table. Key Pension Payment Assumptions. } \\
\hline $\begin{array}{c}\text { Scenario } \\
\text { Model economy }\end{array}$ & $\begin{array}{c}\text { Reference Scenario in } \\
\text { 2014 Actuarial Valuation } \\
\text { (all with medium mortality rate) }\end{array}$ & Real wage growth & Inflation & $\begin{array}{c}\text { Adjustment period years } \\
\text { (basic, employee's) }\end{array}$ & $\begin{array}{c}\text { Macro-indexing factor } \\
\text { (Avg. annual adjustment over 30 years) }\end{array}$ \\
\hline 5.1 Baseline & Scenario G with medium fertility & 1 percent & 0.9 percent & 2038,2031 & -1.37 percent \\
\hline 6.1 Favorable demog. & Scenario G with high fertility & 1 percent & 0.9 percent & 2042,2025 & -1.28 percent \\
\hline 6.3 Improving TFP & Scenario D with medium fertility & $\begin{array}{c}1.5 \text { percent } \\
\text { (1.6 in Actuarial Valuation) }\end{array}$ & 1.4 percent & 2043,2019 & -1.30 percent \\
\hline
\end{tabular}

